Research Article

\title{
Impacts of Climatic Change on Reference Crop Evapotranspiration across Different Climatic Zones of Ningxia at Multi-Time Scales from 1957 to 2018
}

\author{
Ziyang Zhao, ${ }^{1}$ Hongrui Wang $\mathbb{D}^{1}{ }^{1}$ Cheng Wang, ${ }^{2}$ Wangcheng Li, ${ }^{3}$ Hao Chen, \\ and Shuxin Gong ${ }^{1}$ \\ ${ }^{1}$ Beijing Key Laboratory of Urban Hydrological Cycle and Sponge City Technology, College of Water Sciences, \\ Beijing Normal University, Beijing 100875, China \\ ${ }^{2}$ Environment Science Division, Argonne National Laboratory, Lemont, IL 60439, USA \\ ${ }^{3}$ School of Civil and Hydraulic Engineering, Ningxia University, Yinchuan 750021, China
}

Correspondence should be addressed to Hongrui Wang; henrywang@bnu.edu.cn

Received 22 August 2019; Revised 23 December 2019; Accepted 1 February 2020; Published 12 June 2020

Academic Editor: Nir Y. Krakauer

Copyright (C) 2020 Ziyang Zhao et al. This is an open access article distributed under the Creative Commons Attribution License, which permits unrestricted use, distribution, and reproduction in any medium, provided the original work is properly cited.

The impact of global climate change on agroecosystems is growing, affecting reference crop evapotranspiration $\left(\mathrm{ET}_{0}\right)$ and subsequent agricultural water management. In this study, the climate factors temporal trends, the spatiotemporal variation, and the climate driving factors of $\mathrm{ET}_{0}$ at different time scales were evaluated across the Northern Yellow River Irrigation Area (NYR), Central Arid Zone (CAZ), and Southern Mountain Area (SMA) of Ningxia based on 20 climatic stations' daily data from 1957 to 2018. The results showed that the $T_{\text {mean }}$ (daily mean air temperature), $T_{\max }$ (daily maximum air temperature), and $T_{\min }$ (daily minimum air temperature) all had increased significantly over the past 62 years, whilst RH (relative humidity), $U_{2}$ (wind speed at $2 \mathrm{~m}$ height), and SD (sunshine duration) had significantly decreasing trends across all climatic zones. At monthly scale, the ET 0 was mainly concentrated from April to September. And at annual and seasonal scales, the overall increasing trends were more pronounced in NX, NYR, and SMA, while CAZ was the opposite. For the spatial distribution, $\mathrm{ET}_{0}$ presented a trend of rising first and then falling at all time scales. The abrupt change point for climatic factors and $\mathrm{ET}_{0}$ series was obtained at approximately 1990 across all climatic zones, and the $\mathrm{ET}_{0}$ had a long period of $25 \mathrm{a}$ and a short period of $10 \mathrm{a}$ at annual scale, while it was $15 \mathrm{a}$ and $5 \mathrm{a}$ at seasonal scale. RH and $T_{\max }$ were the most sensitive climatic factors at the annual and seasonal scales, while the largest contribution rates were $T_{\max }$ and SD. This study not only is important for the understanding of $\mathrm{ET}_{0}$ changes but also provides the preliminary and elementary reference for agriculture water management in Ningxia.

\section{Introduction}

Evapotranspiration (ET) is not only an important component of the hydrological cycle but also essential for understanding land surface processes in climatology [1]. And the productivity is closely related to actual ET in agricultural research; thus, ET has important implications for improving local agricultural water management [2]. However, the data of ET are insufficient and limited due to lack of monitoring; therefore, many scholars use a variety of methods to study ET from different perspectives. The reference evapotranspiration $\left(\mathrm{ET}_{0}\right)$, which is defined as the potential ET of grass, can be used to prepare input data for hydrology models (e.g., SWAT model), schedule irrigation systems, and calculate the actual evapotranspiration (ET) in a basin or a region [3]. This is because the reference evapotranspiration $\left(\mathrm{ET}_{0}\right)$ has sufficient moisture, and it is not affected by soil factors. Linking $\mathrm{ET}_{0}$ to a specific surface (grass) can provide a reference for ET on other surfaces [2]. In order to revise the reference evapotranspiration $\left(\mathrm{ET}_{0}\right)$ calculation criteria, the Penman-Monteith method has been recommended by Food and Agriculture Organization (FAO) Irrigation and Drainage Paper No. 56 [4]. And due to the easy calculation and ease of data access, the FAO56 has become one of the 
bestselling and most cited publications in the field of water resources management up to now [5].

Climate change has produced profound impact on society and environment. Many global issues are likely to be affected by climate change, such as extreme hydrological cycles, food security, biodiversity loss, and water scarcity $[6,7] . \mathrm{ET}_{0}$, which is the link between water balance and surface energy balance, is considered as a significant indicator for the climate change and the water cycle [8]. And as part of changing climate, $\mathrm{ET}_{0}$ trends directly affect global and regional water resources. In order to assess agricultural demand, hydrological cycle, and ecological changes more effectively, a clear understanding of historical trends and future changes of $\mathrm{ET}_{0}$ and its response to climate change are essential $[9,10]$.

Climate change is intensifying and mainly characterized by a significant increase in temperature due to anthropogenic emissions of active greenhouse gases (such as $\mathrm{CO}_{2}$, $\mathrm{CH}_{4}$, and $\mathrm{N}_{2} \mathrm{O}$ ) [11]. According to the report of IPCC, the average temperature of global land and sea surface showed a linear upward trend of rising by $0.85^{\circ} \mathrm{C}$ from 1880 to 2012, the average temperature increased by $0.78^{\circ} \mathrm{C}$ from 1850 to 1990 , and the average temperature was projected to increase by $1.5^{\circ} \mathrm{C}$ for the end of 21st century [12]. Since the rising trend of air temperature has always existed, $\mathrm{ET}_{0}$ has been increasing globally in the past few decades and reported in the Republic of Moldova [13], Greece [14], Iran [15], and France [16]. However, the $\mathrm{ET}_{0}$ is declining in some areas at the same time, such as northwest China [17], New Zealand [18], United States [19], and southwestern China [20]. Therefore, an increase in global temperature may not lead to the rise in $\mathrm{ET}_{0}$ under any circumstances, which is called as the "evaporation paradox." To explain this problem, many scholars have done a lot of research by quantifying the influence of climate factors on $\mathrm{ET}_{0}$. They concluded that changes in radiation and wind speed dominated the impact of $\mathrm{ET}_{0}$ in some regions $[21,22]$, while water vapor indicators and temperature were the main reasons for changes in other regions $[23,24]$. These contradictory explanations and recent studies show that it is necessary to pay attention to the relationship between $\mathrm{ET}_{0}$ and climate factors in the future research.

The Ningxia Hui Autonomous Region, one of the important parts of "the Belt and Road", is located in the temperate continental arid and semiarid area. The east, west, and north are surrounded by Maowusu, Tengger, and Ulanbu deserts, respectively. And the desertification land area accounts for $53.68 \%$ of the total area [25]. The amount of water resources is limited, and the demand for water has increased dramatically; thus, there is a sharp contradiction between economic development and limited water resources [26]. In the past decade, based on the Ningxia Water Resources Bulletin, the water consumption has increased by two times, and agriculture is the largest water-consuming sector, with more than $85 \%$ of water supplied for irrigation [25]. In addition, water resource is being directed from the agricultural sector to industry and other sectors; thus, food security and agricultural water security are facing severe pressure in Ningxia. $\mathrm{ET}_{0}$ is a key component of the water cycle process and plays an important role in assessing water resources shortage [27]. Consequently, the analysis of $\mathrm{ET}_{0}$ and its response to climate change can not only help to understand climate change but also improve water management.

In general, the main objectives of this study are as follows: (1) to discuss the interannual variation trend of climate factors; (2) to analyze monthly, seasonal, and annual $\mathrm{ET}_{0}$ of spatiotemporal changes; (3) to explore the abrupt change and periodicity of $\mathrm{ET}_{0}$ series; and (4) to quantify the impact of climate factors on $\mathrm{ET}_{0}$ change and identify dominant factors. This research will help to raise awareness of climate change and provide valuable reference for researchers and policymakers to guide regional water management, agricultural production, and conservation of the environment.

\section{Materials and Methods}

To analyze the changes in reference evapotranspiration $\left(\mathrm{ET}_{0}\right)$ over Ningxia at multi-time scales, an approach framework for $\mathrm{ET}_{0}$ analysis pattern selection was proposed. The framework mainly included the climate trend analysis, $\mathrm{ET}_{0}$ spatiotemporal analysis, abrupt change and periodicity analysis, and $\mathrm{ET}_{0}$ influence factors analysis (Figure 1).

2.1. Study Area and Climate Data. The Ningxia Hui Autonomous Region (NX) $\left(35^{\circ} 14^{\prime} \sim 39^{\circ} 23^{\prime} \mathrm{N}, 104^{\circ} 17^{\prime} \sim 107^{\circ} 39^{\prime} \mathrm{E}\right)$ is part of the Yellow River basin and is located among the Alxa Plateau, the North China Plateau, and the Qilian Mountains folds. The area consists of Northern Yellow River irrigation area (NYR), Central Arid Zone (CAZ), and Southern Mountain Area (SMA) and has a total area of $6.6 \times 10^{4} \mathrm{~km}^{2}$ [28] (Figure 2). This region faces a serious shortage of water resources and a huge contradiction between water supply and demand. And it has also led to serious environmental problems due to excessive use of water resources, including soil erosion, water pollution, and deterioration of the ecological environment [29]. Moreover, the seasons are divided into climate standards, namely, spring from March to May, summer from June to August, autumn from September to November, and winter from December to February [30]. In addition, the statistical significance of the linear trend and correlation analysis in this study was labeled as significance levels $p<0.05\left(^{*}\right)$ and $p<0.01\left(^{* *}\right)$ unless otherwise stated.

In Ningxia, 20 climate stations with 62 years (from 1957 to 2018) of climate data were selected (Table 1). The climate data, including daily minimum air temperature $\left(T_{\min },{ }^{\circ} \mathrm{C}\right)$, daily mean air temperature $\left(T_{\text {mean }},{ }^{\circ} \mathrm{C}\right)$, daily maximum air temperature $\left(T_{\max },{ }^{\circ} \mathrm{C}\right)$, sunshine duration $(\mathrm{SD}, \mathrm{h})$, relative humidity $(\mathrm{RH}, \%)$, and wind speed at $2 \mathrm{~m}$ height $\left(U_{2}, \mathrm{~m} / \mathrm{s}\right)$, were downloaded from the National Meteorological Information Center (http://data.cma.cn). The datasets are available because the missing data rate handled by quality control is less than $0.1 \%$, and some missing points were interpolated based on the regression relationship with those of the adjacent stations. 


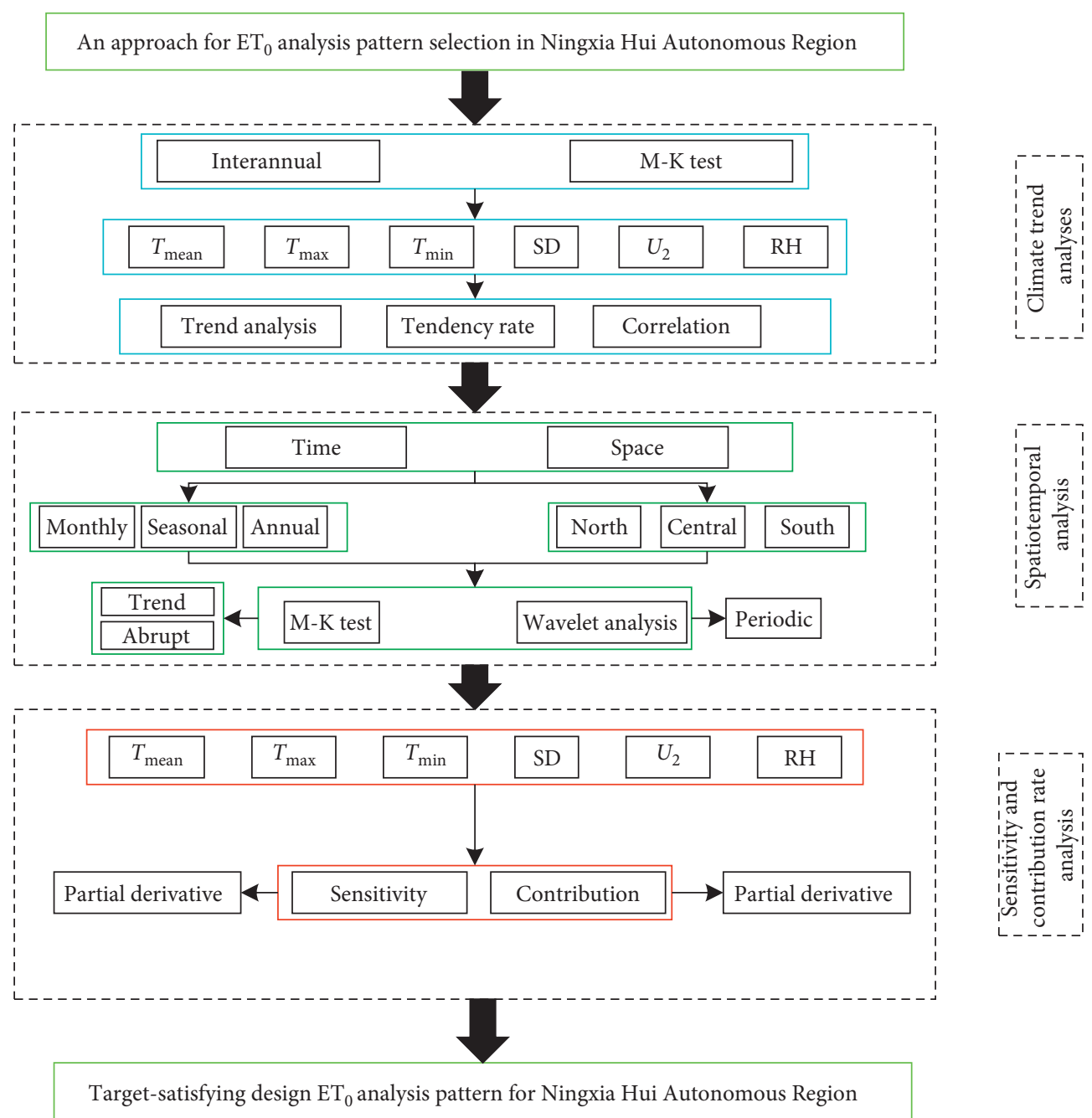

Figure 1: Approach framework, as proposed for ET0 analysis.

2.2. Climate Trend Analyses. Climate tendency rate is a widely used method for studying climate change, which is simple and effective. It is common practice to establish a linear regression equation:

$$
x_{i}=a+b t_{i}, \quad(i=1,2, \cdots, n),
$$

where $x_{i}$ is the climate factors with a sample size of $n, t_{i}$ is the time corresponding to $x_{i}, b$ is the regression coefficient, and $a$ is the regression constant. $b$ is the annual change rate of climate factors, while its symbol indicates the change direction. When $b>0$, it indicates an increasing trend with time; when $b<0$, it indicates a decreasing trend with time. $b \times 10$ is known as the climate tendency rate, indicating the change rate of climate factors every 10 years.

2.3. $E T_{0}$ Estimation. Analyzing the spatiotemporal characteristics of $\mathrm{ET}_{0}$ is helpful to understand the distribution and management of agricultural water requirements. The Penman-Monteith (PM) method, which is recommended by the Food and Agriculture Organization (FAO), has been widely used for calculating $\mathrm{ET}_{0}$ [31]. The model was used in this study to estimate daily $\mathrm{ET}_{0}$ and cumulative monthly, seasonal, and annual $\mathrm{ET}_{0}$ :

$$
\mathrm{ET}_{0}=\frac{0.408 \Delta\left(R_{n}-G\right)+\gamma(900 /(T+273)) u_{2}\left(e_{s}-e_{a}\right)}{\Delta+\gamma\left(1+0.34 u_{2}\right)},
$$

where $\mathrm{ET}_{0}$ is the daily reference crop evapotranspiration $\left(\mathrm{mm} \cdot \mathrm{day}^{-1}\right), \Delta$ is the slope of vapor pressure curve $\left(\mathrm{kPa} \cdot{ }^{\circ} \mathrm{C}^{-1}\right), \quad R_{n}$ is the net radiation at crop surface $\left(\mathrm{MJ} \cdot \mathrm{m}^{-2} \cdot \mathrm{day}^{-1}\right), \quad G$ is the soil heat flux density $\left(\mathrm{MJ} \cdot \mathrm{m}^{-2} \cdot\right.$ day $\left.^{-1}\right), \gamma$ is the psychrometric constant $\left(\mathrm{kPa} \cdot{ }^{\circ} \mathrm{C}^{-1}\right)$, $T$ is the average daily air temperature $\left({ }^{\circ} \mathrm{C}\right), u_{2}$ is the wind speed at $2 \mathrm{~m}\left(\mathrm{~ms}^{-1}\right), e_{s}$ is the saturation vapor pressure $(\mathrm{kPa})$, and $e_{a}$ is the actual vapor pressure $(\mathrm{kPa})$.

2.4. Mann-Kendall Test Analysis. Analyzing the abrupt change point is helpful for understanding the evolution trend of $\mathrm{ET}_{0}$ and determining the demarcation point of natural factors and human factors. Since the sample does not need to follow a specific distribution, the Mann-Kendall nonparametric test is recommended by the World Climate 


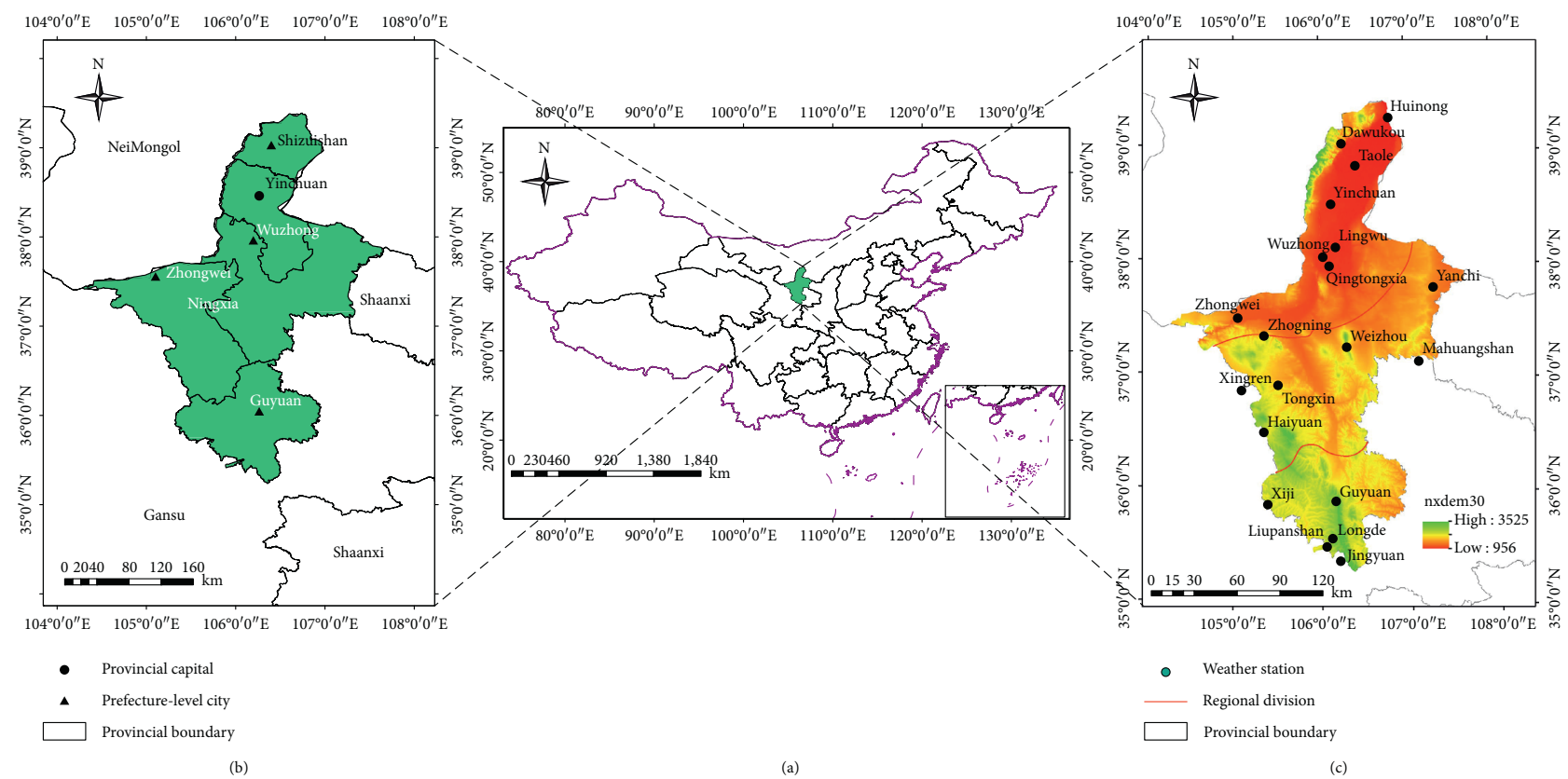

FIGURE 2: Location and administrative division of the study area: (a) a map of China with the study area shown in green; (b) a political map of the Ningxia Hui Autonomous Region with the location of the urban center; (c) a topographical map of the Ningxia Hui Autonomous Region with the distribution of the climate stations in the study area and climate stations are marked by solid black circle.

Organization and is widely used in climate trend analysis [32]:

$$
\begin{aligned}
\mathrm{UF}_{k} & =\frac{s_{k}-E\left(s_{k}\right)}{\sqrt{\operatorname{Var}\left(s_{k}\right)}}, k=1,2,3, \ldots, \\
s_{k} & =\sum_{i=1}^{k} r_{i}, \\
r_{i} & = \begin{cases}1, & \text { if } x_{i}>x_{j}, \\
0, & \text { else, }\end{cases} \\
j & =1,2, \ldots, i, \\
& \left\{\begin{array}{l}
\mathrm{UB}_{k}=-\mathrm{UF}_{k}, \\
k=n+1-k,
\end{array}\right. \\
k & =1,2, \ldots, n,
\end{aligned}
$$

where $\mathrm{UF}_{K}$ is a sequence of statistics calculated in time series $x$ and $\mathrm{UB}_{K}$ is a sequence of statistics calculated in reverse order of time series $x$. Uf $f_{i}$ is a standard normal distribution; if a significance level $\alpha$ is given and $\left|\mathrm{Uf}_{i}\right|>U_{(\alpha / 2)}$, it indicates a significant trend change in the sequence. And if there is an intersection point between the two curves of $\mathrm{UF}_{K}$ and $\mathrm{UB}_{K}$, this is the moment when the abrupt changes starts.

2.5. Continuous Wavelet Analysis. Wavelet analysis offers the possibility to better study time series problems, which can clearly reveal the multiple change cycles hidden in the time series, fully reflects the changing trend of the system in different time scales, and makes a qualitative estimation of the future development trend of the system. Although the continuous wavelet of the Morlet function was previously in the field of communication, it has been widely used in hydrological climate research with the interdisciplinary development [33]:

$$
\begin{aligned}
\psi(t) & =e^{i c t} e^{\left(-t^{2} / 2\right)}, \\
W_{f}(a, b) & =|a|^{(-1 / 2)} \int_{R} f(t) \psi^{((t-b) / a)} \mathrm{d} t, \\
\operatorname{Var}(a) & =\int_{R}\left|W_{f}(a, b)\right|^{2} \mathrm{~d} b,
\end{aligned}
$$

where $\psi(t)$ is the wavelet basic function, $W_{f}(a, b)$ is the wavelet variation coefficient, $\operatorname{Var}(a)$ is the wavelet variance, $a$ is the scale factor of the wavelet period length, $b$ is the time factor of time translation, $t$ is time, $f(t)$ is the time series number, and $R$ is the real number field.

2.6. Sensitivity Analysis and Contribution Rate Assessment. In order to quantitatively study the close relationship between $\mathrm{ET}_{0}$ and different climatic factors, sensitive coefficient and contribution rate are the most commonly used methods by many scholars.

2.6.1. Sensitivity Analysis. Compared with other sensitivity analysis methods, the partial correlation coefficient method can analyze the complex nonlinear relationship of each factor by controlling the influence of other factors; thus, it is suitable for global sensitivity analysis, which is widely used in nonlinear dynamic problems [34]: 
TABLE 1: Basic information for the national climate stations used in the study area.

\begin{tabular}{|c|c|c|c|c|c|}
\hline Region & Station code & Name & Longitude $\left({ }^{\circ} \mathrm{E}\right)$ & Latitude $\left({ }^{\circ} \mathrm{N}\right)$ & Altitude $(\mathrm{m})$ \\
\hline \multirow{9}{*}{ NYR } & 53518 & Shitanjing & 106.45 & 39.27 & 1466.4 \\
\hline & 53519 & Huinong & 106.46 & 39.13 & 1093.1 \\
\hline & 53615 & Taole & 106.42 & 38.48 & 1102.9 \\
\hline & 53614 & Yinchuan & 106.12 & 38.28 & 1111.6 \\
\hline & 53619 & Lingwu & 106.18 & 38.12 & 1117.3 \\
\hline & 53617 & Qingtongxia & 106.04 & 38.02 & 1132.2 \\
\hline & 53612 & Wuzhong & 106.11 & 37.98 & 1129.0 \\
\hline & 53704 & Zhongwei & 105.11 & 37.32 & 1226.6 \\
\hline & 53705 & Zhongning & 105.41 & 37.29 & 1184.4 \\
\hline \multirow{6}{*}{ CAZ } & 53723 & Yanchi & 107.23 & 37.48 & 1350.4 \\
\hline & 53881 & Weizhou & 106.29 & 37.28 & 1382.9 \\
\hline & 53727 & Mahuangshan & 107.07 & 37.17 & 1713.0 \\
\hline & 53810 & Tongxin & 105.54 & 36.58 & 1340.7 \\
\hline & 53707 & Xingren & 105.15 & 36.93 & 1698.8 \\
\hline & 53806 & Haiyuan & 105.39 & 36.34 & 1854.8 \\
\hline \multirow{5}{*}{ SMA } & 53817 & Guyuan & 106.16 & 36 & 1754.2 \\
\hline & 53903 & Xiji & 105.43 & 35.58 & 1917.9 \\
\hline & 53910 & Liupanshan & 106.12 & 35.67 & 2842.8 \\
\hline & 53914 & Longde & 106.06 & 35.62 & 2079.5 \\
\hline & 53916 & Jingyuan & 106.2 & 35.5 & 1949.0 \\
\hline
\end{tabular}

$$
S_{x}=\lim _{\Delta x \rightarrow 0}\left(\frac{\left(\Delta \mathrm{ET}_{0} / \mathrm{ET}_{0}\right)}{(\Delta x / x)}\right)=\frac{\partial \mathrm{ET}_{0}}{\partial x} \cdot \frac{x}{\mathrm{ET}_{0}},
$$

where $S_{x}$ is the sensitive coefficient; $\Delta \mathrm{ET}_{0}$ and $\Delta x$ are the change values of $\mathrm{ET}_{0}$ and climate factors, respectively; and positive or negative of $S_{x}$, respectively, indicates that $\mathrm{ET}_{0}$ increases or decreases with the increase in climate factors.

2.6.2. Contribution Rate. In order to determine the underlying causes of changes in $\mathrm{ET}_{0}$, sensitivity analysis needs to be combined with actual changes in climatic factors; thus, it is necessary to analyze the contribution rate of climatic factors to $\mathrm{ET}_{0}$ [35]:

$$
\begin{aligned}
C_{x} & =S_{x} \cdot R c_{x}, \\
\mathrm{Rc}_{x} & =\frac{n \cdot \text { Trend }_{x}}{\bar{x}} \cdot 100 \%,
\end{aligned}
$$

where $S_{x}$ is the sensitive coefficient, $C_{x}$ is the contribution rate of climate factors to $\mathrm{ET}_{0}$ changes, $\mathrm{Rc}_{x}$ is the multiyear change rate of climate factors, Trend $\mathrm{d}_{x}$ is the annual climate tilt rate of climate factor $x, \bar{x}$ is the multiyear absolute average of climate factors, and $n$ is the length of the time series.

\section{Results}

\subsection{Climate Factors Analysis}

3.1.1. Temporal Trends of Climate Factors. From the climate data of each station from 1957 to 2018 (62 years), the average value of climate factors and the climate tendency rate was statistically calculated (Figure 3 and Table 2). The climate in Ningxia had undergone significant changes in climate factors from the past 62 years. Spatially averaged $T_{\text {mean }}, T_{\text {max }}$, and $T_{\min }$ all increased significantly $(p<0.01)$, and the change rates were $0.34^{\circ} \mathrm{C} / 10 \mathrm{a}, 0.31^{\circ} \mathrm{C} / 10 \mathrm{a}$, and $0.51^{\circ} \mathrm{C} / 10 \mathrm{a}$, respectively.
Conversely, the $\mathrm{RH}$ and $U_{2}$ had a significant downward trend $(p<0.05)$, and the change rates were $0.42 / 10 \mathrm{a}$ and $0.10 \mathrm{~m} / \mathrm{s} /$ $10 \mathrm{a}$, respectively. Although the $\mathrm{SD}$ was also showing a downward trend, the effect was not significant. Across the three different regions (NYR, CAZ, and SMA), $T_{\text {mean }}, T_{\text {max }}$, and $T_{\min }$ also had significantly increased with similar variation. The increasing rates of $T_{\text {mean }}\left(0.38^{\circ} \mathrm{C} / 10 \mathrm{a}\right), T_{\max }\left(0.36^{\circ} \mathrm{C} /\right.$ $10 \mathrm{a})$, and $T_{\min }\left(0.54^{\circ} \mathrm{C} / 10 \mathrm{a}\right)$ were the largest in the NYR, while the CAZ was the smallest $\left(0.31^{\circ} \mathrm{C} / 10 \mathrm{a}, 0.24^{\circ} \mathrm{C} / 10 \mathrm{a}\right.$, and $0.48^{\circ} \mathrm{C} /$ $10 \mathrm{a}$, respectively). Although the significant downward trends $(p<0.01)$ were found for RH in NYR and $U_{2}$ in CAZ, the RH, $\mathrm{SD}$, and $U_{2}$ also showed a downward trend in the three different regions. The decreasing rates of $\mathrm{RH}(0.81 \% / 10 \mathrm{a})$ in the NYR and SD $(0.40 \mathrm{~h} / 10 \mathrm{a})$ and $U_{2}(0.11 \mathrm{~m} / \mathrm{s} / 10 \mathrm{a})$ in SMA were largest, while $\mathrm{RH}(0.06 \% / 10 \mathrm{a})$ and $\mathrm{SD}(0.04 \mathrm{~h} / 10 \mathrm{a})$ in CAZ and $U_{2}(0.08 \mathrm{~m} / \mathrm{s} / 10 \mathrm{a})$ in NYR were smallest.

Generally speaking, under the influence of global climate change in recent 62 years, the overall climate of Ningxia had been warming and drying, and the temperature has increased significantly. The $T_{\text {mean }}$ rise rate was $0.34^{\circ} \mathrm{C} / 10 \mathrm{a}$, which was lower than the rise rate of $0.37^{\circ} \mathrm{C} / 10 \mathrm{a}$ in the northwest region of China, higher than the $0.23^{\circ} \mathrm{C} / 10 \mathrm{a}$ of Chinese average $[36,37]$, also higher than the $0.22^{\circ} \mathrm{C} / 10 \mathrm{a}$ of global average $[38,39]$. And the rising rate was ranked as NYR $>$ SMA $>$ CAZ. Furthermore, the $\mathrm{RH}$ decreased in varying degrees, while the decreasing rate was also sorted by NYR $>$ SMA $>$ CAZ. The SD and $U_{2}$ had similar downward trend of change, and the decreasing rate was ranked as $\mathrm{SMA}=\mathrm{CAZ}>\mathrm{NYR}$.

Additionally, the changes in climate factors during the year are basically consistent in all regions (Figure 4 ). The temperature ( $T_{\text {mean }}, T_{\text {max }}$, and $T_{\text {min }}$ ) showed a rising trend and then a decreasing trend, in which the maximum value appeared in July. And the temperature was ranked as CAZ > NYR > SMA. The RH performed a trend of falling first, then rising, and finally falling, in which the maximum value is September and the minimum value is April. 


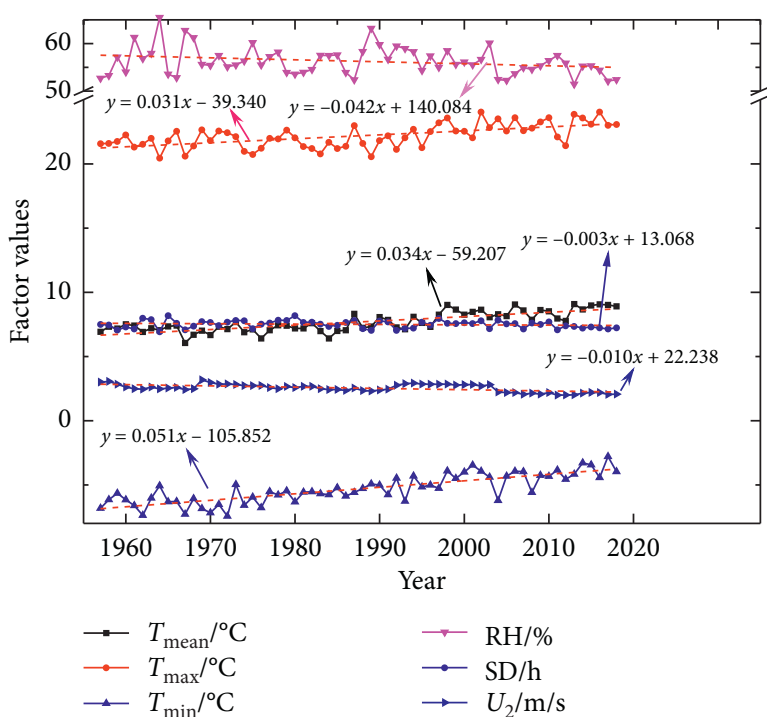

(a)

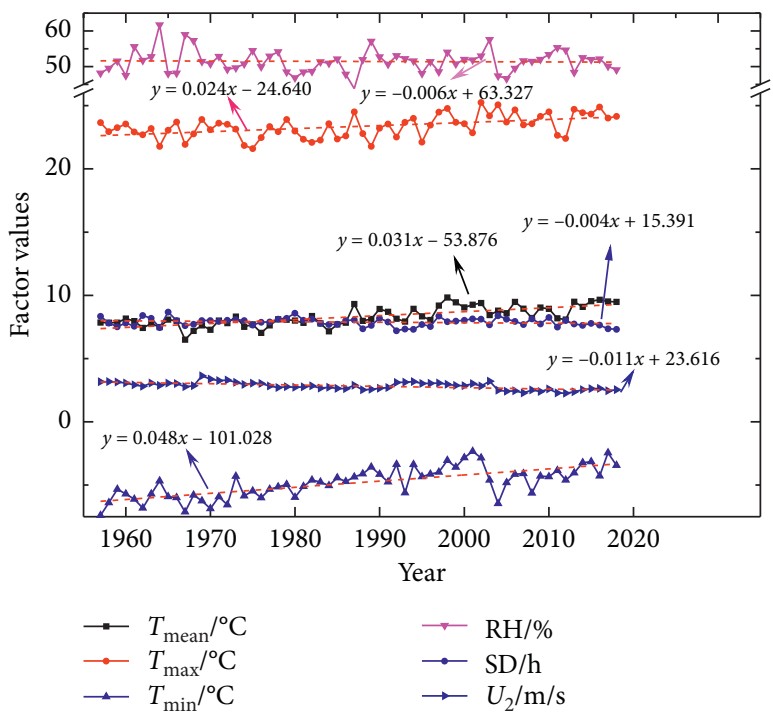

(c)

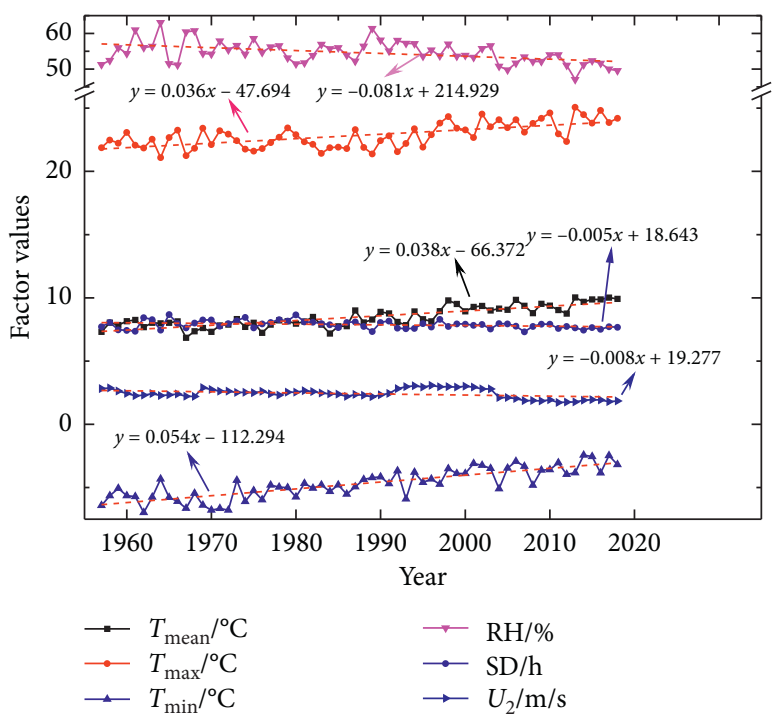

(b)

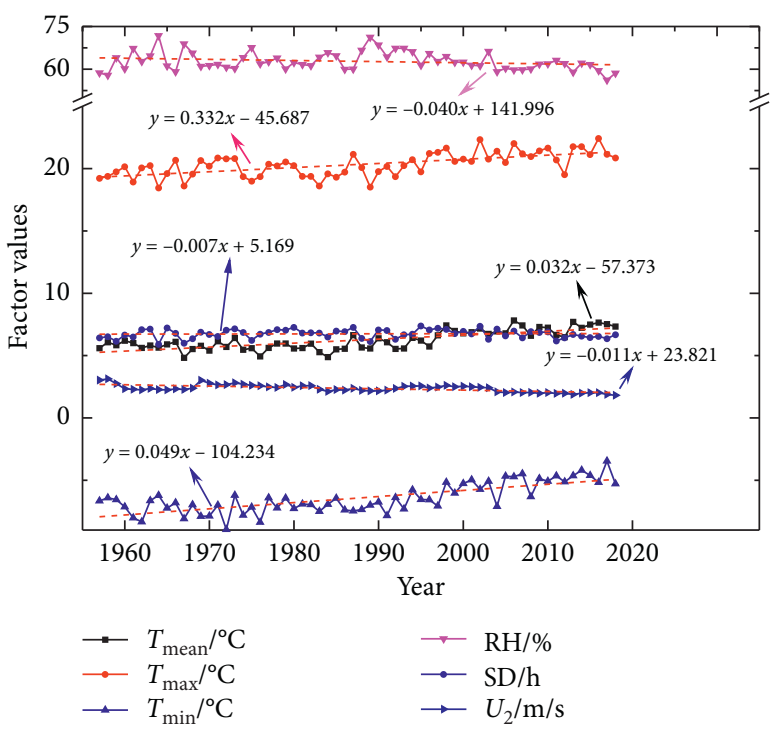

(d)

FIGURE 3: Annual variations in spatially averaged values of climate data (average temperature $\left(T_{\text {mean }}\right)$, maximum temperature $\left(T_{\max }\right)$, minimum temperature $\left(T_{\min }\right)$, relative humidity $(\mathrm{RH})$, sunshine duration $(\mathrm{SD})$, and wind speed $\left(U_{2}\right)$ from 1957 to 2018 in different climate zones): (a) Ningxia (NX); (b) Northern Yellow River irrigation area (NYR); (c) Central Arid Zone (CAZ); (d) Southern Mountain Area (SMA).

And the RH was sorted by SMA $>$ NYR $>$ CAZ. The SD and $U_{2}$ were relatively stable throughout the year without violent fluctuations, while they were ranked as CAZ $>$ NYR $>$ SMA.

3.1.2. Abrupt Change Test Analysis of Climate Factors. Although there had been a trend of warming and drying in Ningxia in recent 62 years, when did this trend begin and what form did it take? The Mann-Kendall abrupt change test method was used to analyze the climatic factors in this study (Table 2). The results showed that there were different abrupt change points in each factor. Importantly, since the $\mathrm{ET}_{0}$ in NX had an abrupt change point in 1990 (Figure 5), the whole research period was divided into two periods (i.e., from 1957 to 1990 and from 1991 to 2018) for the convenience of analysis.

In general, the temperature trend changes were consistent in all regions. The $T_{\text {mean }}$ and $T_{\text {min }}$ had increased significantly $(p<0.01)$ from two periods, while the $T_{\max }$ decreased significantly from 1957 to 1990 and increased from 1991 to 2018 . The $T_{\text {mean }}, T_{\max }$, and $T_{\min }$ changed by $0.094^{\circ} \mathrm{C} / 10 \mathrm{a},-0.044^{\circ} \mathrm{C} / 10 \mathrm{a}$, and $0.451^{\circ} \mathrm{C} / 10 \mathrm{a}$ from 1957 to 1990 while changed by $0.451^{\circ} \mathrm{C} / 10 \mathrm{a}, 0.446^{\circ} \mathrm{C} / 10 \mathrm{a}$, and $0.548^{\circ} \mathrm{C} / 10$ a from 1991 to 2018 in NX, respectively. And this result showed that the extreme temperatures phenomenon in Ningxia was easing. The average value of $T_{\text {mean }}$ from two periods was both ranked as NYR $>$ CAZ $>$ SMA, while the largest value was $7.92^{\circ} \mathrm{C} / 10 \mathrm{a}$ and $9.19^{\circ} \mathrm{C} / 10 \mathrm{a}$; the smallest value was $5.73^{\circ} \mathrm{C} / 10 \mathrm{a}$ and $6.87^{\circ} \mathrm{C} / 10 \mathrm{a}$, respectively. And the average 
TABLE 2: Trend analyses of climate factors with Mann-Kendall test and climate tendency rate.

\begin{tabular}{|c|c|c|c|c|c|c|c|c|}
\hline \multirow{2}{*}{ Climate region } & \multirow{2}{*}{ Climate factor } & \multicolumn{3}{|c|}{ Climate tendency rate } & \multicolumn{3}{|c|}{ Climate factors average value } & \multirow{2}{*}{ Change point } \\
\hline & & $1957 \sim 1990$ & $1991 \sim 2018$ & $1957 \sim 2018$ & $1957 \sim 1990$ & $1991 \sim 2018$ & 1957 2018 & \\
\hline \multirow{6}{*}{ NX (whole) } & $T_{\text {mean }}\left({ }^{\circ} \mathrm{C}\right)$ & $0.094^{* *}$ & $0.451^{* *}$ & $0.34^{* *}$ & 7.16 & 8.33 & 7.69 & 1993 \\
\hline & $T_{\max }\left({ }^{\circ} \mathrm{C}\right)$ & $-0.044^{* *}$ & $0.446^{* *}$ & $0.31^{* *}$ & 21.66 & 22.82 & 22.18 & 1995 \\
\hline & $T_{\min }\left({ }^{\circ} \mathrm{C}\right)$ & $0.385^{* *}$ & $0.548^{* *}$ & $0.51^{* *}$ & -6.05 & -4.41 & -5.31 & 1989 \\
\hline & RH (\%) & $0.121^{*}$ & $-1.598^{*}$ & $-0.42^{*}$ & 56.82 & 55.59 & 56.27 & 1992 \\
\hline & $\mathrm{SD}(\mathrm{h})$ & 0.039 & -0.094 & -0.03 & 7.55 & 7.44 & 7.50 & 1994 \\
\hline & $U_{2}(\mathrm{~m} / \mathrm{s})$ & $-0.108^{*}$ & $-0.365^{*}$ & $-0.10^{*}$ & 2.63 & 2.43 & 2.54 & 1988 \\
\hline \multirow{6}{*}{ NYR } & $\mathrm{T}_{\text {mean }}\left({ }^{\circ} \mathrm{C}\right)$ & $0.145^{* *}$ & $0.531^{* *}$ & $0.38^{* *}$ & 7.92 & 9.19 & 8.49 & 1992 \\
\hline & $T_{\max }\left({ }^{\circ} \mathrm{C}\right)$ & $-0.051^{* *}$ & $0.643^{* *}$ & $0.36^{* *}$ & 22.28 & 23.55 & 22.85 & 1994 \\
\hline & $T_{\min }\left({ }^{\circ} \mathrm{C}\right)$ & $0.454^{* *}$ & $0.57^{* *}$ & $0.54^{* *}$ & -5.47 & -3.75 & -4.70 & 1989 \\
\hline & RH (\%) & $0.036^{* *}$ & $-2.446^{* *}$ & $-0.81^{* *}$ & 55.70 & 53.25 & 54.59 & 1996 \\
\hline & SD (h) & 0.032 & -0.096 & -0.05 & 7.98 & 7.76 & 7.88 & 1995 \\
\hline & $U_{2}(\mathrm{~m} / \mathrm{s})$ & -0.057 & -0.551 & -0.08 & 2.47 & 2.36 & 2.42 & 1991 \\
\hline \multirow{6}{*}{ CAZ } & $T_{\text {mean }}\left({ }^{\circ} \mathrm{C}\right)$ & $0.193^{* *}$ & $0.263^{* *}$ & $0.31^{* *}$ & 7.83 & 8.92 & 8.32 & 1992 \\
\hline & $T_{\max }\left({ }^{\circ} \mathrm{C}\right)$ & $-0.063^{* *}$ & $0.288^{* *}$ & $0.24^{* *}$ & 22.93 & 23.90 & 23.37 & 1995 \\
\hline & $T_{\min }\left({ }^{\circ} \mathrm{C}\right)$ & $0.665^{* *}$ & $0.135^{* *}$ & $0.48^{* *}$ & -5.48 & -3.99 & -4.81 & 1988 \\
\hline & RH (\%) & -0.444 & 0.071 & -0.06 & 51.42 & 51.45 & 51.43 & 1989 \\
\hline & SD (h) & 0.017 & -0.011 & -0.04 & 7.95 & 7.81 & 7.88 & 1989 \\
\hline & $U_{2}(\mathrm{~m} / \mathrm{s})$ & $-0.157^{* *}$ & $-0.278^{* *}$ & $-0.11^{* *}$ & 2.93 & 2.71 & 2.83 & 1994 \\
\hline \multirow{6}{*}{ SMA } & $\mathrm{T}_{\text {mean }}\left({ }^{\circ} \mathrm{C}\right)$ & $0.029^{* *}$ & $0.558^{* *}$ & $0.32^{* *}$ & 5.73 & 6.87 & 6.24 & 1990 \\
\hline & $T_{\max }\left({ }^{\circ} \mathrm{C}\right)$ & $-0.019^{* *}$ & $0.407^{* *}$ & $0.33^{* *}$ & 19.79 & 21.00 & 20.34 & 1992 \\
\hline & $T_{\min }\left({ }^{\circ} \mathrm{C}\right)$ & $0.013^{* *}$ & $0.939^{*}$ & $0.49^{* *}$ & -7.19 & -5.51 & -6.43 & 1991 \\
\hline & RH (\%) & $0.774^{*}$ & $-2.42^{*}$ & $-0.4^{*}$ & 63.34 & 62.08 & 62.77 & 1990 \\
\hline & SD (h) & 0.1 & -0.175 & -0.4 & 6.73 & 6.76 & 6.75 & 1988 \\
\hline & $U_{2}(\mathrm{~m} / \mathrm{s})$ & -0.109 & $-0.267^{*}$ & -0.11 & 2.48 & 2.21 & 2.36 & 1987 \\
\hline
\end{tabular}

value trend of $T_{\min }$ was similar to $T_{\text {mean }}$. Moreover, the average value of $T_{\max }$ was sorted by CAZ $>$ NYR $>$ SMA. The result showed that it is hotter in CAZ and colder in SMA. RH in NX changed significantly $(p<0.01)$ by $0.121 \% / 10 \mathrm{a}$ and $-1.598 \% / 10$ a from two periods, respectively. It was also found across the three different climate regions, and this also implies the trend of drying. SD had an increased trend from 1957 to 1991 and a decreased trend from 1991 to 2018 in all regions, but the effect was not significant. The region with largest change was SMA, where increased by $0.1 \mathrm{~h} / 10 \mathrm{a}$ from 1957 to 1991 and decreased by $0.175 \mathrm{~h} / 10 \mathrm{a}$ from 1991 to 2018 . $U_{2}$ had decreased significantly $(p<0.05)$ by $0.108 \mathrm{~m} / \mathrm{s} / 10$ a from 1957 to 1991 and $0.365 \mathrm{~m} / \mathrm{s} / 10$ a from 1991 to 2018 in NX, respectively. Although the three climate regions all had the similar trends, the effect was not significant in NYR and SMA.

3.2. Trend Analysis of $E T_{0}$. There are significant differences in the temporal and spatial distribution of $\mathrm{ET}_{0}$ due to the variability in the climate system and the complexity of the geographical environment. In this study, the time scale was divided into monthly, seasonal, and annual scales, and the spatial scale was divided into NYR, CAZ, and SMA.

3.2.1. Analysis at Monthly Scale. Monthly averaged $\mathrm{ET}_{0}$ at each region from 1957 to 2018 is listed in Table 3 and Figure 6 . The average monthly $\mathrm{ET}_{0}$ was sorted as $\mathrm{CAZ}$ $(108.06 \mathrm{~mm})>$ NYR $(105.70 \mathrm{~mm})>\mathrm{NX}(101.87 \mathrm{~mm})>\mathrm{SMA}$ $(83.02 \mathrm{~mm})$. The $\mathrm{ET}_{0}$ ranged from $33.49 \mathrm{~mm} \cdot \mathrm{month}^{-1}$ to $168.95 \mathrm{~mm} \cdot \mathrm{month}^{-1}$ with a total value of $1222.41 \mathrm{~mm}$ over the NX, while the extremum ratio was 5.04. In the three climate regions, both the $\mathrm{ET}_{0}$ of NYR and CAZ were larger than NX, but the extremum ratio of NYR (5.80) exceeded $\mathrm{CAZ}$ (4.48). The $\mathrm{ET}_{0}$ and extremum ration of SMA was the smallest among NYR, CAZ, and NX, while its values were $996.19 \mathrm{~mm}$ and 4.43, respectively. In general, $\mathrm{ET}_{0}$ showed a trend of rising first and then falling during the year across all the regions. And the time of the monthly $\mathrm{ET}_{0}$ extreme was almost the same in different regions, the maximum value was in May or June, and the minimum value was in December. In addition, the $\mathrm{ET}_{0}$ from May to July was larger during the whole year in all regions, accounting for more than $40 \%$ of the total $\mathrm{ET}_{0}$, respectively.

In order to compare the spatial distribution of $\mathrm{ET}_{0}$ in different seasons, the typical months were used for analysis (Figure 7). Because autumn in Ningxia is too short to be representative, this study chose the typical months of spring (April), summer (August), and winter (December) for analysis. Climate and topography changed from north to south; $\mathrm{ET}_{0}$ showed a trend of first falling, then rising, and finally falling in the typical months. And the $\mathrm{ET}_{0}$ was the largest in the north and middle, while the smallest in the south. In April, $\mathrm{ET}_{0}$ was the highest in Weizhou, Mahuangshan, Xingren, and Zhongning, and Huinong and Shitanjing were also higher. The overall change ranged from $90 \mathrm{~mm}$ to $160 \mathrm{~mm}$, while it is in line with the climate characteristics of Ningxia's fast warming and strong wind. In August, the semiarid climate in Ningxia was characterized by less rainfall and longer sunshine, and $\mathrm{ET}_{0}$ continued to increase with the range of variation from $100 \mathrm{~mm}$ to $165 \mathrm{~mm}$. In December, $\mathrm{ET}_{0}$ was significantly reduced compared to April and August due to the severe cold, and 


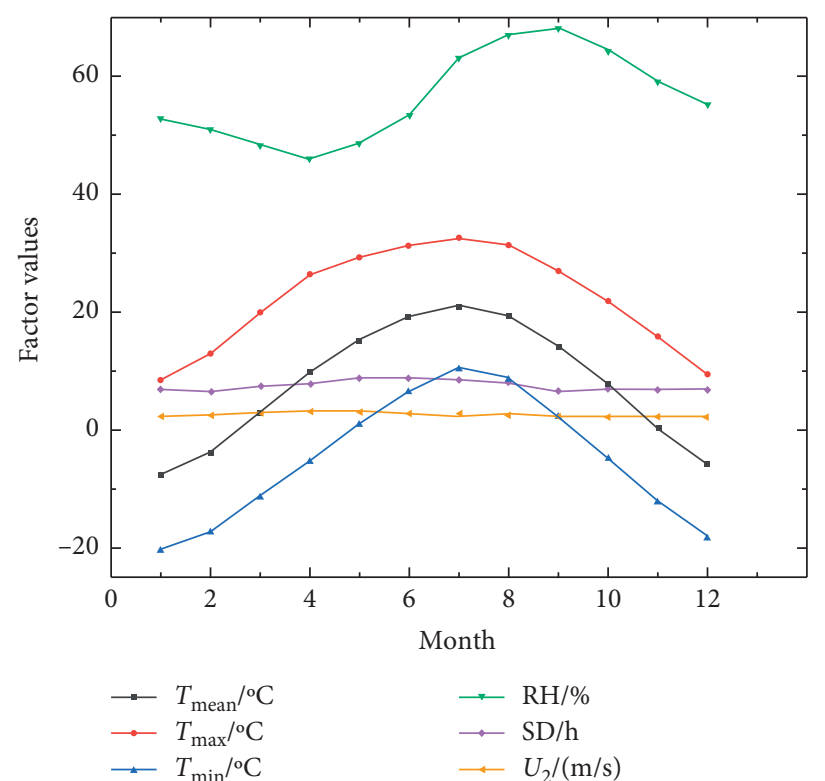

(a)

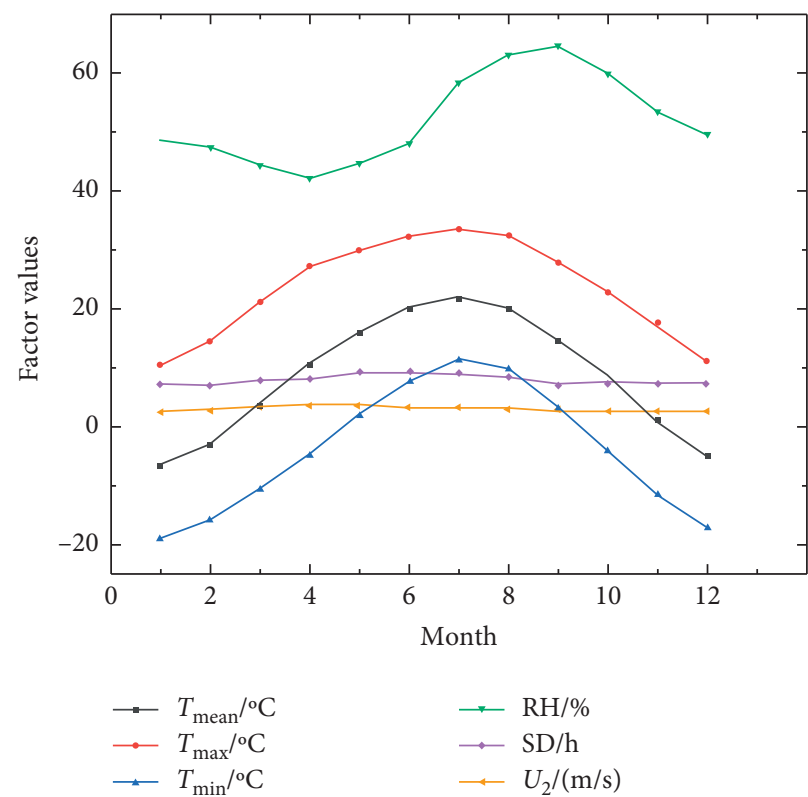

(c)

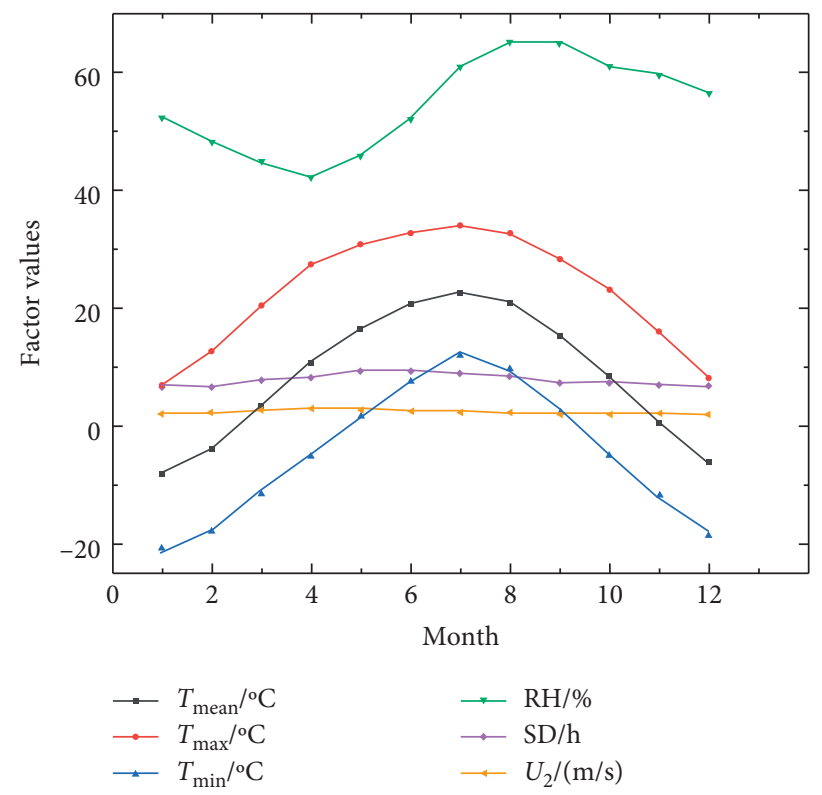

(b)

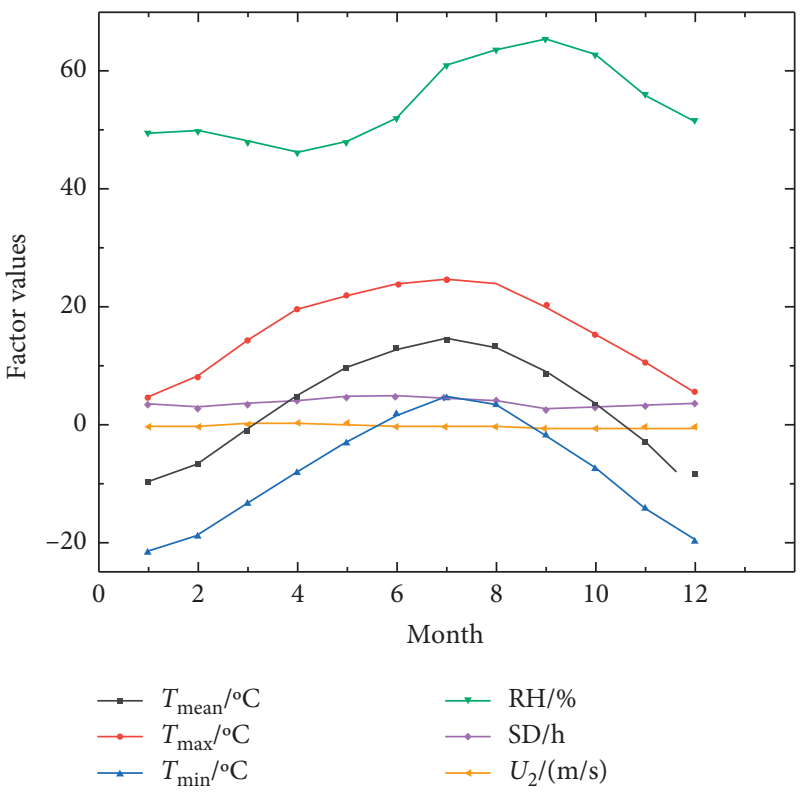

(d)

FIGURE 4: Monthly variations in spatially averaged values of climate data (average temperature $\left(T_{\text {mean }}\right)$, maximum temperature $\left(T_{\max }\right)$, minimum temperature $\left(T_{\min }\right)$, relative humidity $(\mathrm{RH})$, sunshine duration $(\mathrm{SD})$, and wind speed $\left(U_{2}\right)$ from 1957 to 2018 in different climate zones): (a) Ningxia (NX); (b) Northern Yellow River irrigation area (NYR); (c) Central Arid Zone (CAZ); (d) Southern Mountain Area (SMA).

although the average was between $20 \mathrm{~mm}$ and $45 \mathrm{~mm}$, the Xingren and Haiyuan were still relatively higher.

3.2.2. Analysis at Seasonal Scale. Seasonal $\mathrm{ET}_{0}$ is a special indicator that can be used to reflect changes in $\mathrm{ET}_{0}$ at different stages of the year. Temporal variations in seasonal $\mathrm{ET}_{0}$ from each climate region from 1957 to 2018 exhibit two main trends (Figure 8). CAZ showed a downward trend in the four stages of spring, summer, autumn, and winter, while
NX, NYR, and SMA showed an upward trend. And this was consistent with the change in the annual scale. In spring, the $\mathrm{ET}_{0}$ was $427.07 \mathrm{~mm}, 423.56 \mathrm{~mm}$, and $324.01 \mathrm{~mm}$ in NYR, CAZ, and SMA, respectively, accounting for 36.36\%, $36.06 \%$, and $27.58 \%$ of $\mathrm{ET}_{0}$ in NX (whole), respectively. And the $\mathrm{ET}_{0}$ was sorted as NYR $>\mathrm{CAZ}>\mathrm{SMA}$. In addition, the $\mathrm{ET}_{0}$ in NX, NYR, and SMA all increased significantly $(p<0.01)$, and the change rate was $2.78 \mathrm{~mm} / 10 \mathrm{a}, 5.45 \mathrm{~mm} /$ $10 \mathrm{a}$, and $1.51 \mathrm{~mm} / 10 \mathrm{a}$, respectively. Conversely, the CAZ had a significant downward trend $(p<0.05)$, and the change 

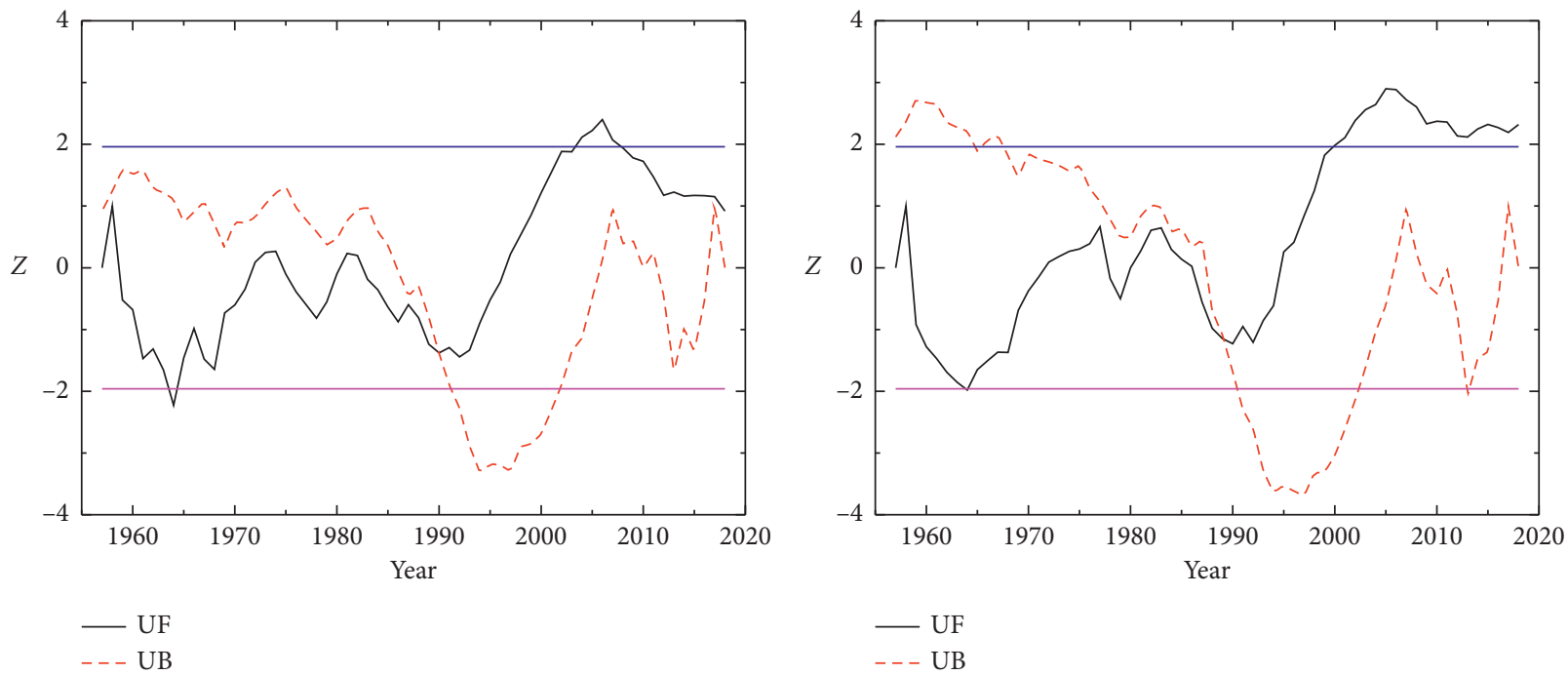

(a)
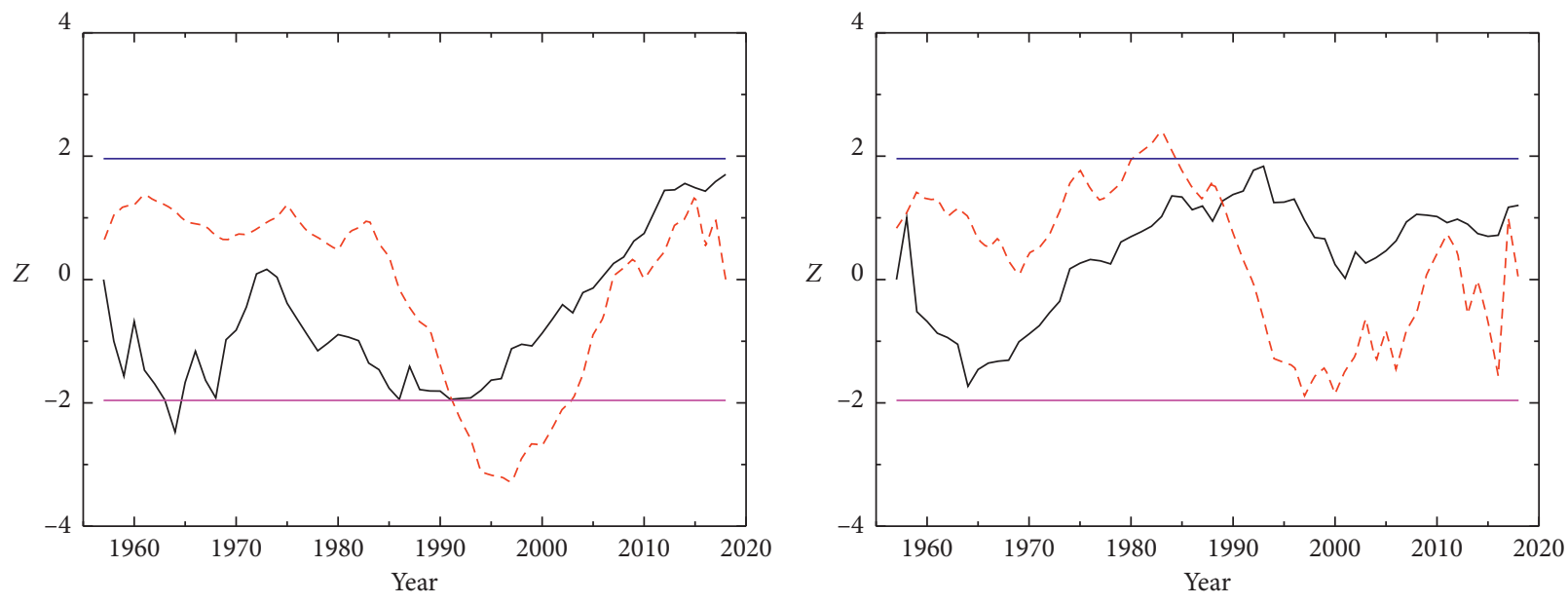

$-\mathrm{UF}$
$--\mathrm{UB}$

$-\mathrm{UF}$
$--\mathrm{UB}$

(c)

(d)

FIgURE 5: Mann-Kendall test of each region at annual scale: (a) NX; (b) NYR; (c) CAZ; (d) SMA.

TABLE 3: Monthly average of $\mathrm{ET}_{0}$ in Ningxia and each region.

\begin{tabular}{|c|c|c|c|c|}
\hline Month & NYR & CAZ & SMA & NX (whole) \\
\hline 1 & 33.14 & 40.71 & 32.32 & 35.24 \\
\hline 2 & 52.74 & 56.01 & 42.65 & 51.70 \\
\hline 3 & 101.20 & 102.16 & 77.28 & 96.70 \\
\hline 4 & 148.84 & 144.67 & 110.39 & 139.90 \\
\hline 5 & $\begin{array}{l}177.03 \\
(\max )\end{array}$ & 176.73 & 136.35 & 168.80 \\
\hline 6 & 174.90 & $\begin{array}{l}179.75 \\
(\max )\end{array}$ & $\begin{array}{c}137.90 \\
(\max )\end{array}$ & $\begin{array}{c}168.95 \\
(\max )\end{array}$ \\
\hline 7 & 174.69 & 174.59 & 134.13 & 166.55 \\
\hline 8 & 147.84 & 147.81 & 117.75 & 141.81 \\
\hline 9 & 103.82 & 102.39 & 78.60 & 98.35 \\
\hline 10 & 77.05 & 77.63 & 57.56 & 73.33 \\
\hline 11 & 46.61 & 54.15 & 40.14 & 47.58 \\
\hline 12 & $30.49(\mathrm{~min})$ & $40.07(\mathrm{~min})$ & $31.11(\min )$ & 33.49 (min) \\
\hline Average & 105.70 & 108.06 & 83.02 & 101.87 \\
\hline Total & 1268.34 & 1296.67 & 996.19 & 1222.41 \\
\hline
\end{tabular}

rate was $0.80 \mathrm{~mm} / 10 \mathrm{a}$. Compared with the spring, the trends in summer, autumn, and winter were similar except for the proportion of $\mathrm{ET}_{0}$ in NYR and CAZ, and they were all showed as CAZ > NYR > SMA (Table 4). In order to better understand the changing trend of $\mathrm{ET}_{0}$, this study was divided into two time periods (from 1958 to 190 and from 1991 to 2018), which is consistent with the analysis of climatic factors (Table 5). $\mathrm{ET}_{0}$ tendency rate mainly showed two trends: the downward trend in the first stage and the upward trend in the second stage in NYR and SMA, while the CAZ had always shown a downward trend. Additionally, this study found that the ordering of $\mathrm{ET}_{0}$ tendency rate was consistent in the two periods of three regions, which was showed as spring $>$ summer $>$ winter $>$ autumn.

In terms of spatial distribution, $\mathrm{ET}_{0}$ varies in different regions and seasons. But in general, it showed a trend of increase first and then decreased from north to south, and 


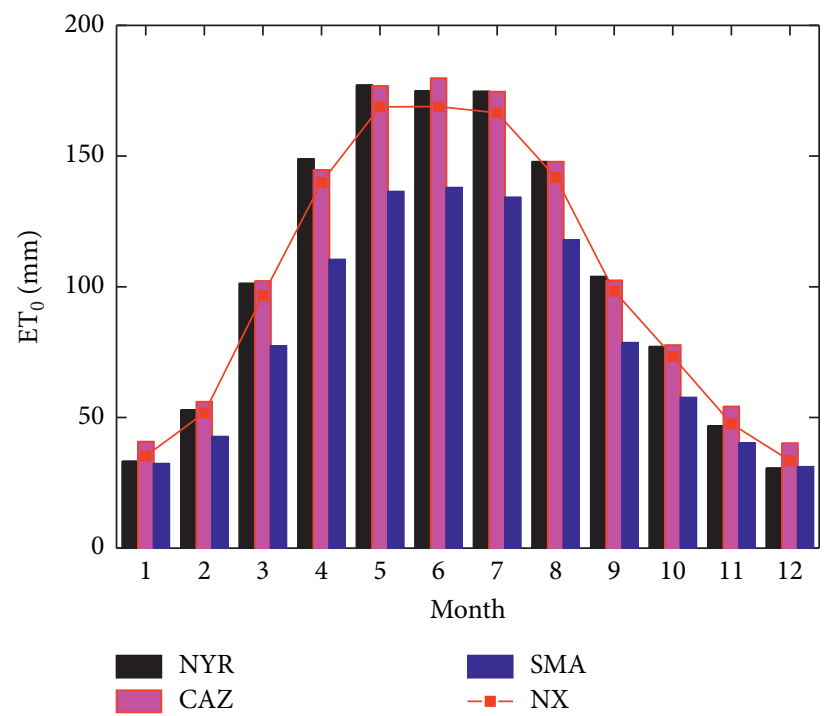

Figure 6: Monthly average of $\mathrm{ET}_{0}$ in Ningxia and each region.
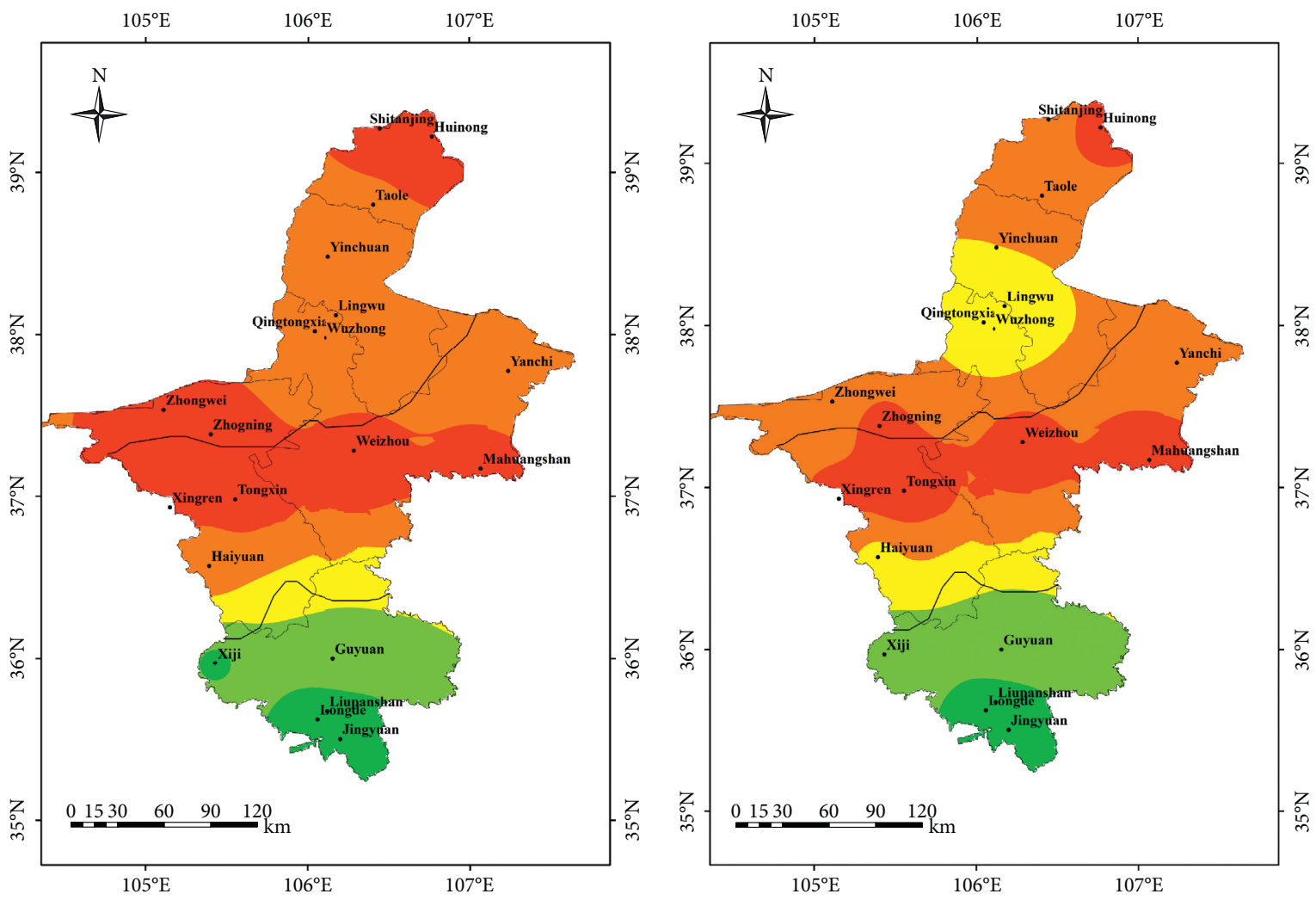

$\mathrm{ET}_{0}(\mathrm{~mm})$

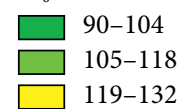

$\mathrm{ET}_{0}(\mathrm{~mm})$

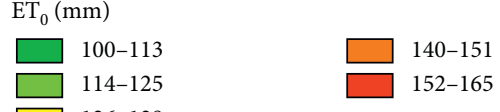

119-132

133-146 $147-160$

(a) (b)

Figure 7: Continued. 


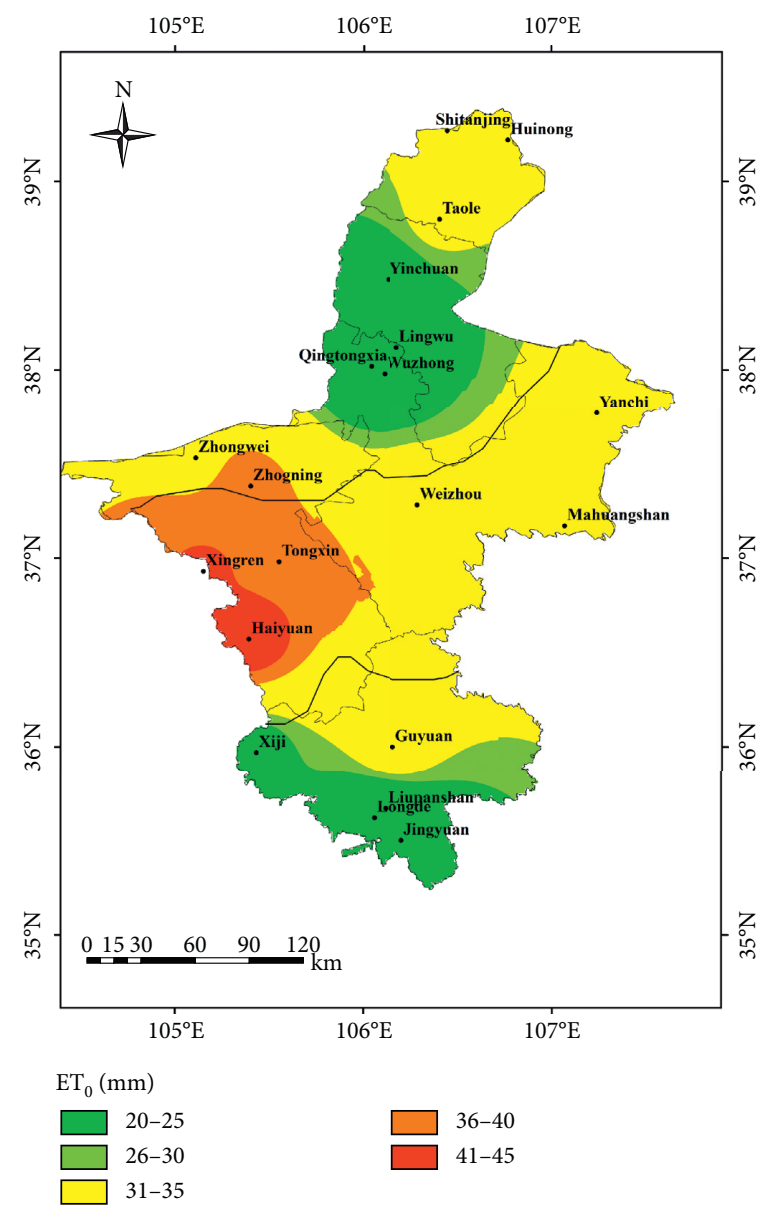

(c)

FIgure 7: Spatial distribution of $\mathrm{ET}_{0}$ at different times: (a) April; (b) August; (c) December.

gradually increased from east to west (Figure 9). The high value area of $\mathrm{ET}_{0}$ presented two distinct distribution regions, namely, the Shitanjing and Huinong in the north and the Tongxin and Xingren in the middle. The low value area was mainly distributed in the south of Liupanshan, Jingyuan, and Longde. It was worth noting that the size of $\mathrm{ET}_{0}$ in Lingwu, Qingtongxia, and Wuzhong has always been in the middle position. The $\mathrm{ET}_{0}$ in Yanchi and Mahuangshan was special, where the spring and autumn were relatively large and the summer and winter were relatively small. In addition, the $\mathrm{ET}_{0}$ in spring was significantly higher than the autumn, and the $\mathrm{ET}_{0}$ in summer was significantly higher than other seasons. Overall, it was sorted as summer $>$ spring $>$ autumn $>$ winter, which was consistent with the local climate characteristics of fast spring, short summer heat, cool autumn early, and long winter and cold.

3.2.3. Analysis at Annual Scale. The $\mathrm{ET}_{0}$ in each climate zone had similar trend in the past 62 years (Figure 10 and Table 6). NX, NYR, and SMA $(p<0.01)$ showed significant growth trends of $5.19 \mathrm{~mm} / 10 \mathrm{a}, 12.12 \mathrm{~mm} / 10 \mathrm{a}$, and $5.09 \mathrm{~mm} /$ $10 \mathrm{a}$, respectively, while the CAZ decreased at a trend rate of $4.52 \mathrm{~mm} / 10 \mathrm{a}$. And the change rate of different regions was ranked as NYR $>\mathrm{NX}>\mathrm{SMA}>\mathrm{CAZ}$. In particular, although the temperature of $\mathrm{CAZ}$ was rising, $\mathrm{ET}_{0}$ showed a downward trend, indicating that there was "evaporation paradox" in parts of Ningxia. Overall, the annual $\mathrm{ET}_{0}$ ranking was $\mathrm{CAZ}$ $(1296.67 \mathrm{~mm})>\mathrm{NYR} \quad(1268.34 \mathrm{~mm})>\mathrm{NX} \quad(1222.41 \mathrm{~mm})$ $>$ SMA (996.19 mm), while the extreme ratio was ranked as NYR (1.30) > SMA (1.29)> CAZ (1.28) > NX (1.27). In addition, it was similar to the monthly scale for the maximum and minimum of annual $\mathrm{ET}_{0}$, with the trend of both NYR and CAZ being greater than NX and CAZ less than NX.

The spatial distribution characteristics of $\mathrm{ET}_{0}$ have significant regional (Figure 11). As the terrain changes from north to south, $\mathrm{ET}_{0}$ showed a trend of decline first, then rise, and finally decline. Located at the southern of Ningxia, the SMA is cool and humid, and the $T_{\text {mean }}$ was $2.25^{\circ} \mathrm{C}$ and $2.08^{\circ} \mathrm{C}$ lower than NYR and CAZ, respectively, while the RH larger by $8.18 \%$ and $8.02 \%$, respectively. Thus, $\mathrm{ET}_{0}$ in SMA was smaller than the NYR and CAZ. CAZ, located in the middletemperate and semiarid zone, is a typical continental climate with strong drought and heavy evaporation. Compared with before the abrupt change point of 1990 , the $T_{\text {mean }}$ rose by $1.3^{\circ} \mathrm{C}$ and the rainfall dropped by $4.2 \%$; thus, the $\mathrm{ET}_{0}$ of CAZ was larger than the NYR and SMA. Particularly, the $\mathrm{ET}_{0}$ of NYR was larger in the north climate stations, while the 

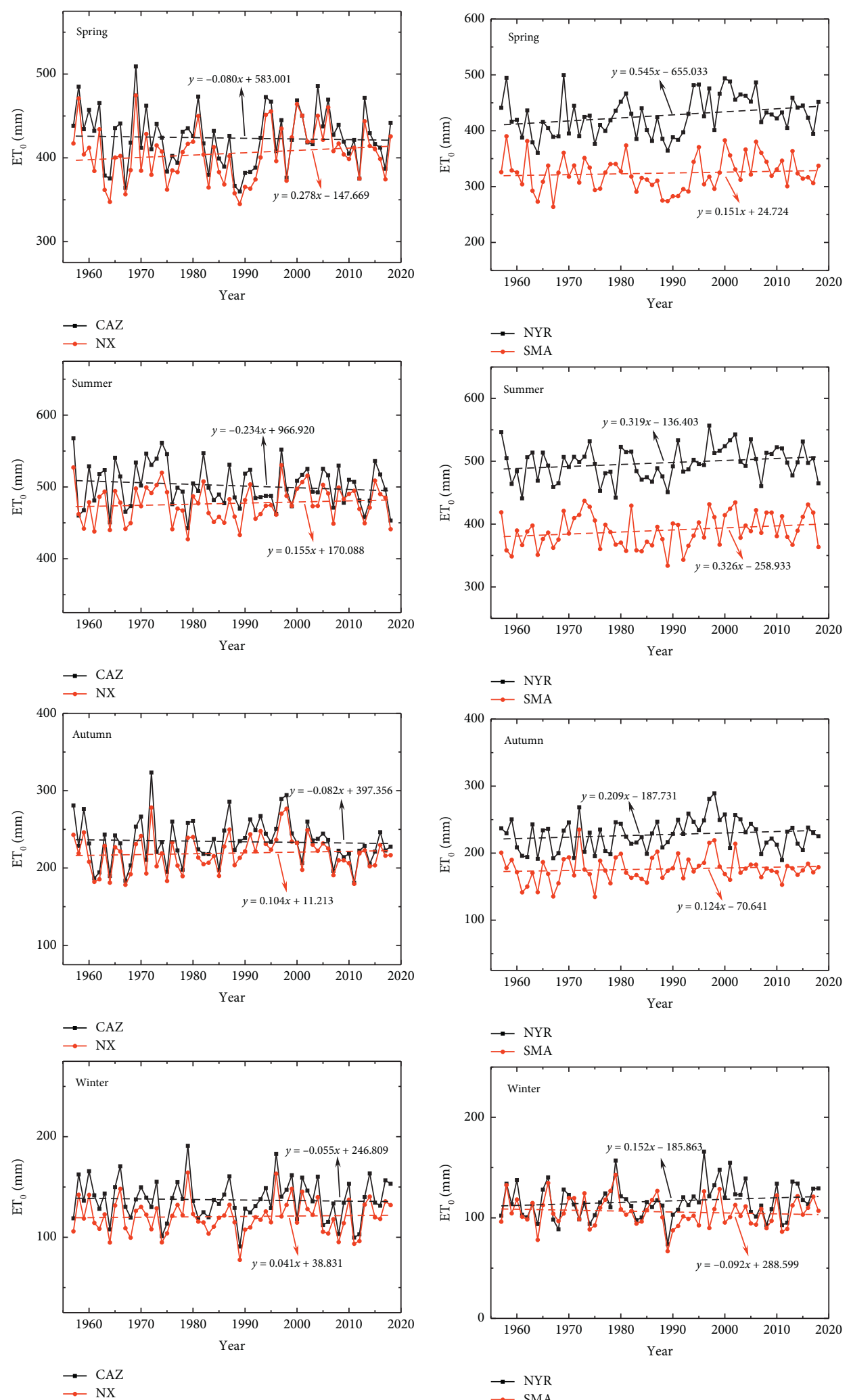

(a)

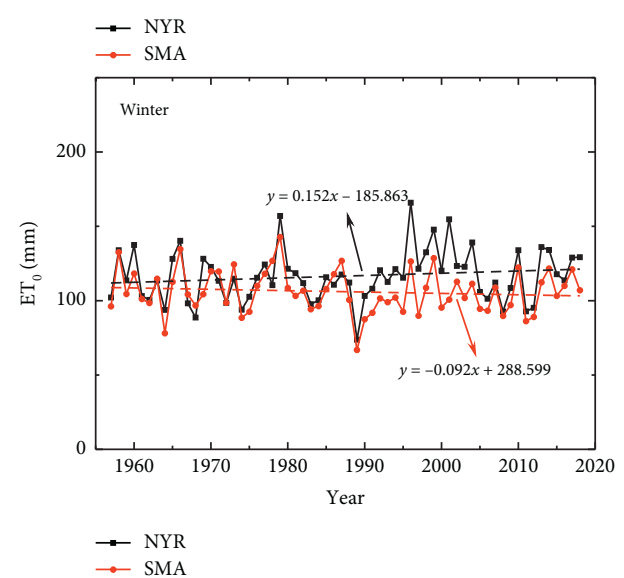

(b)

FIGURE 8: Temporal variations in seasonal $\mathrm{ET}_{0}$ (spring, summer, autumn, and winter) from 1957 to 2018 over the NX, NYR, CAZ, and SMA. 
TABLE 4: The seasonal $\mathrm{ET}_{0}(\mathrm{~mm})$ and proportion (\%) from 1957 to 2018 over the NYR, CAZ, and SMA.

\begin{tabular}{lcccr}
\hline Region & Spring & Summer & Autumn & Winter \\
\hline NYR & $427.07(26.36 \%)$ & $497.25(35.80 \%)$ & $227.48(35.66 \%)$ & $116.54(32.40 \%)$ \\
CAZ & $423.56(36.06 \%)$ & $501.79(36.13 \%)$ & $234.17(36.70 \%)$ & $137.15(38.12 \%)$ \\
SMA & $324.01(27.58 \%)$ & $389.83(28.07 \%)$ & $176.31(27.64 \%)$ & $106.03(29.48 \%)$ \\
\hline
\end{tabular}

TABLE 5: Trend analyses of $\mathrm{ET}_{0}$ in different seasons over the NX, NYR, CAZ, and SMA.

\begin{tabular}{|c|c|c|c|c|}
\hline \multirow{2}{*}{ Climate region } & \multirow{2}{*}{ Season } & \multicolumn{3}{|c|}{$\mathrm{ET}_{0}$ tendency rate } \\
\hline & & $1957 \sim 1990$ & $1991 \sim 2018$ & $1957 \sim 2018$ \\
\hline \multirow{4}{*}{ NX (whole) } & Spring & -5.74 & 4.64 & 2.78 \\
\hline & Summer & -3.96 & 3.50 & 1.55 \\
\hline & Autumn & -0.91 & 0.39 & 1.04 \\
\hline & Winter & -2.94 & 1.73 & 0.41 \\
\hline \multirow{4}{*}{ NYR } & Spring & -6.35 & 4.48 & 5.45 \\
\hline & Summer & -5.03 & 3.49 & 3.19 \\
\hline & Autumn & -0.33 & 1.32 & 2.09 \\
\hline & Winter & -2.71 & 3.21 & 1.52 \\
\hline \multirow{4}{*}{ CAZ } & Spring & -5.27 & -5.02 & -0.80 \\
\hline & Summer & -3.29 & -2.58 & -2.34 \\
\hline & Autumn & -1.38 & -1.12 & -0.82 \\
\hline & Winter & -3.09 & -2.24 & -0.55 \\
\hline \multirow{4}{*}{ SMA } & Spring & -9.93 & 5.25 & 1.51 \\
\hline & Summer & -3.47 & 5.12 & 3.26 \\
\hline & Autumn & -1.65 & 1.46 & 1.24 \\
\hline & Winter & -1.49 & 2.72 & 0.92 \\
\hline
\end{tabular}

others were relatively smaller. And this was principally due to the long SD $(8.44 \mathrm{~h} / \mathrm{d})$ and high $U_{2}(2.82 \mathrm{~m} / \mathrm{s})$ in the north climate stations of NYR.

\subsection{Mann-Kendall Test and Wavelet Analysis of ET}

3.3.1. Analysis at Annual Scale. In the past 62 years, $\mathrm{ET}_{0}$ had shown a trend of first drop and then rise in NX, NYR, CAZ, and SMA, while the abrupt change points were 1990, 1990 (the same to NX), 1991, and 1989, respectively (Figure 5). NX and NYR had a clear upward trend in the 21st century $(Z>1.96)$, and CAZ showed an obvious downward trend in the 1970s $(Z<1.96)$, while the SMA did not have a significant trend of upward and downward. Furthermore, the solid line is a positive value, indicating that $\mathrm{ET}_{0}$ is more than the multiyear average value. And the dashed line is negative, indicating that $\mathrm{ET}_{0}$ is less than the multiyear average value. The junction of the solid line and the dotted line indicates the change point of $\mathrm{ET}_{0}$. The long and short periods of $\mathrm{ET}_{0}$ in NX and NYR were $25 \mathrm{a}$ and $10 \mathrm{a}$, respectively, with the $10 \mathrm{a}$ being the most significant (Figure 12). Similarly, the periods of $\mathrm{ET}_{0}$ in SMA were $10 \mathrm{a}$ and $5 \mathrm{a}$. Nevertheless, the CAZ was special with one period of $15 \mathrm{a}$.

3.3.2. Analysis at Seasonal Scale. From the seasonal scale of Ningxia, the performance of $\mathrm{ET}_{0}$ could be divided into two stages: the alternate change of the early rise and decline to the stable rise in the later period (Figure 13). The abrupt change point in spring, summer, and autumn was the same
(1990), while the abrupt change point in winter was earlier (1980). There was an obvious upward trend in the 21st century $(z>1.96)$ in summer, autumn, and winter. But in spring, the trend was not significant. Seasonal periods all showed the similar trends. $\mathrm{ET}_{0}$ had a long period of $15 \mathrm{a}$ and a short period of 5 a over the entire time domain in spring, summer, autumn, and winter (Figure 14). Take the 15a period in spring as an example; the time point of larger $\mathrm{ET}_{0}$ was the early 1960s and 1980s, while the smaller ET $\mathrm{ET}_{0}$ was the late 1960s, 1970s, and 1990s.

\subsection{Sensitive Coefficient and Contribution Rate Analysis}

3.4.1. Analysis at Annual Scale. Based on equation (5), the sensitive coefficients between $\mathrm{ET}_{0}$ and other six climate factors were obtained (Table 7). All regions had the similar trends, $T_{\text {mean }}, T_{\max }, T_{\min }, \mathrm{SD}$, and $U_{2}$ were positive values, while the RH was negative. This suggested that the increase in $\mathrm{RH}$ caused the decline of $\mathrm{ET}_{0}$, and other climatic factors were the opposite. Moreover, among the 20 climate stations, the average minimum and maximum climate factors for the sensitive coefficient of $\mathrm{ET}_{0}$ were $T_{\min }(0.08)$ and $\mathrm{RH}(0.46)$, respectively. In general, the sensitive coefficient of Ningxia was ranked as $\mathrm{RH}>T_{\max }>U_{2}>T_{\text {mean }}>\mathrm{SD}>T_{\text {min }}$. Additionally, there were two trends of the sensitive coefficient in spatial distribution, the $T_{\text {max }}, T_{\text {mean }}$, and $\mathrm{RH}$ increased first from north to south and then decreased, while the SD, $T_{\min }$, and $U_{2}$ were the opposite. Thus, the CAZ was special, where the sensitive coefficient of $T_{\max }, T_{\text {mean }}$, and $\mathrm{RH}$ was the largest, and other climate factors were the smallest. 

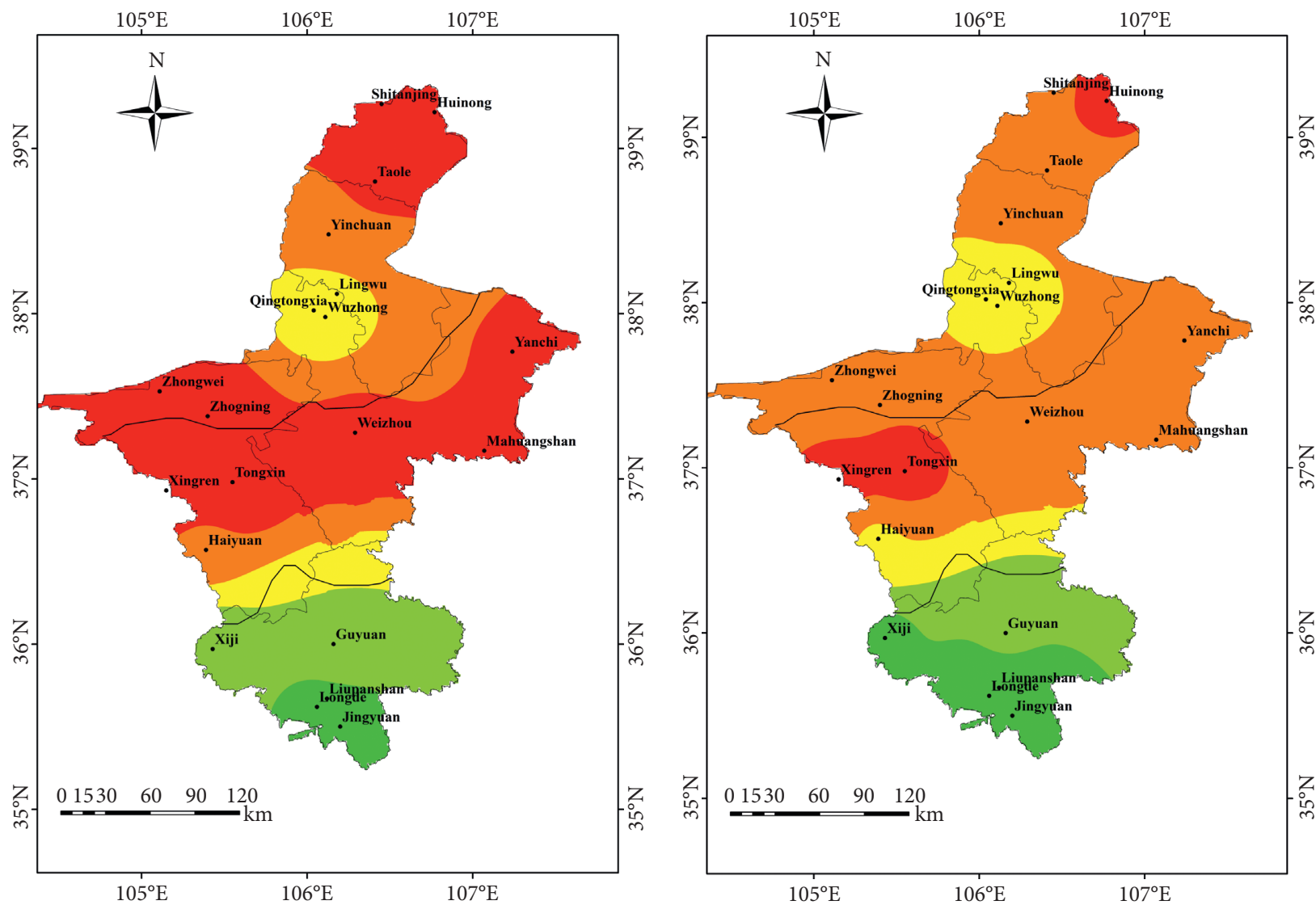

$\mathrm{ET}_{0}(\mathrm{~mm})$
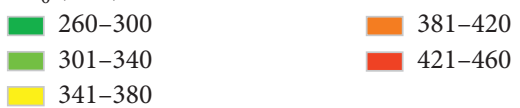

$\mathrm{ET}_{0}(\mathrm{~mm})$

- 350-390

- 391-430

- 471-510

- 341-380

431-470

(a)

(b)

FIgURE 9: Continued. 

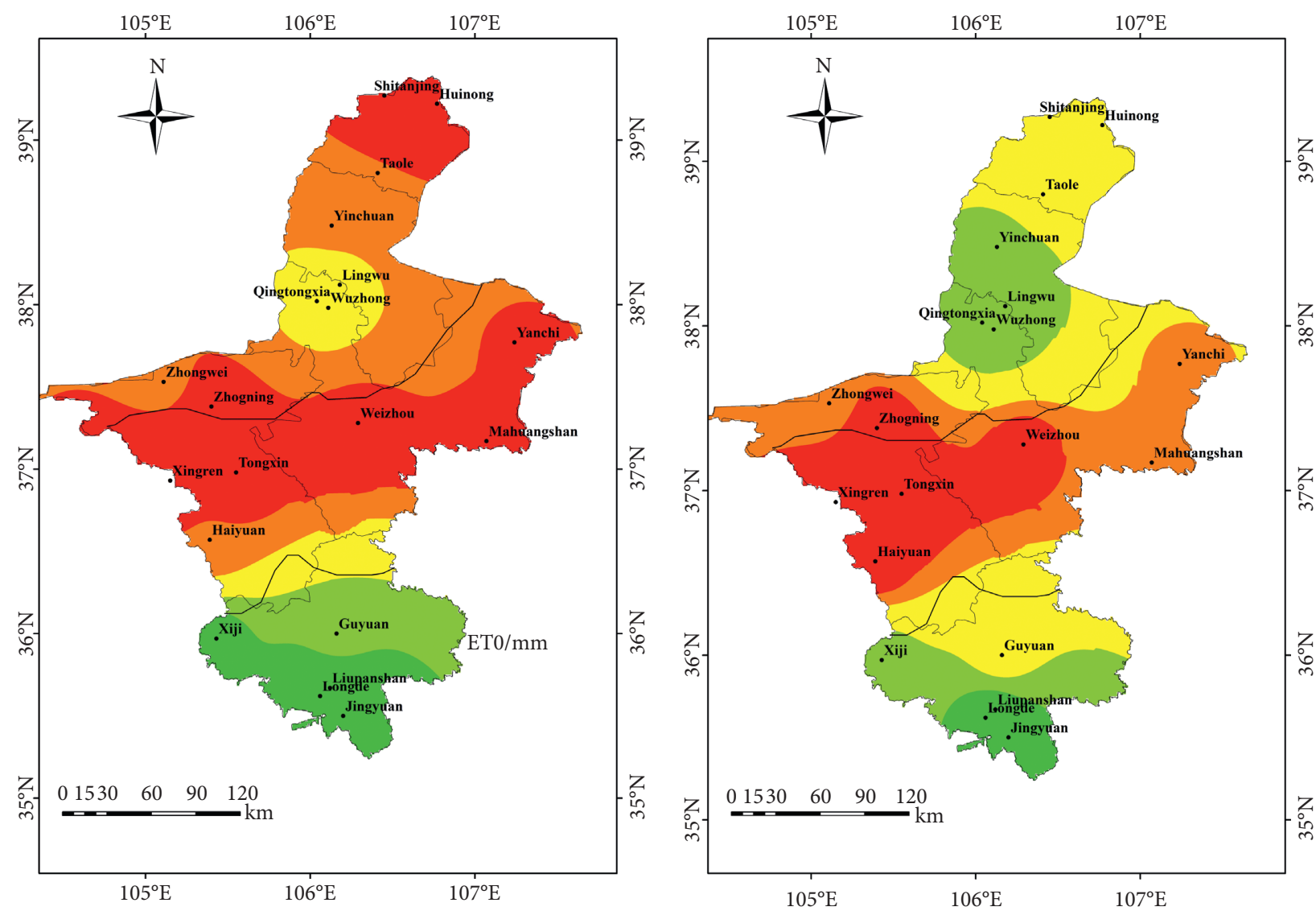

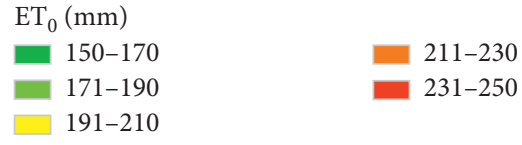

(c)

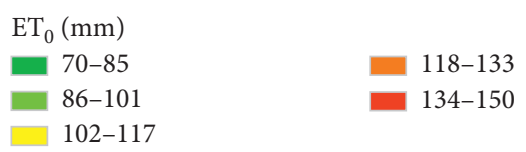

(d)

FIgURE 9: Spatial distribution of average $\mathrm{ET}_{0}$ at different times: (a) spring; (b) summer; (c) autumn; (d) winter.

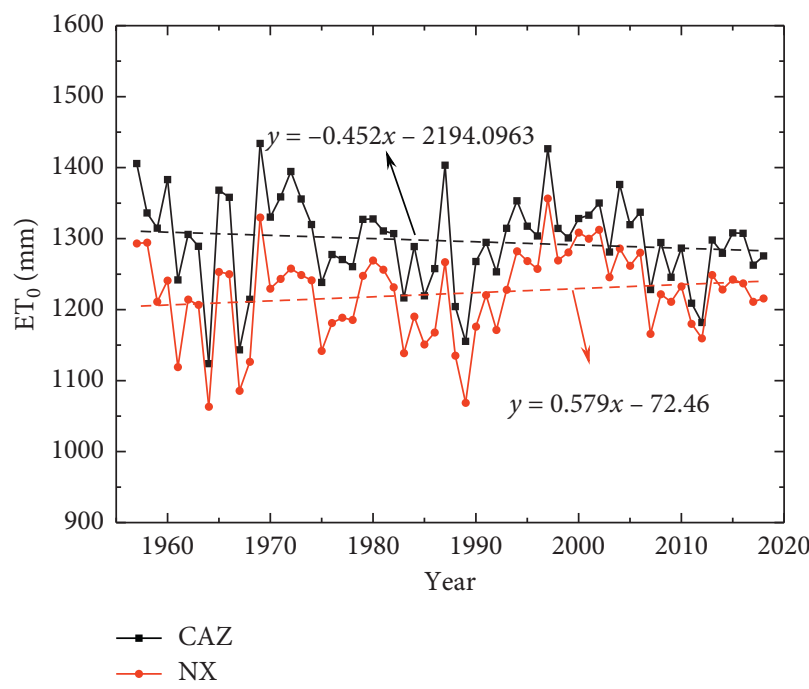

(a)

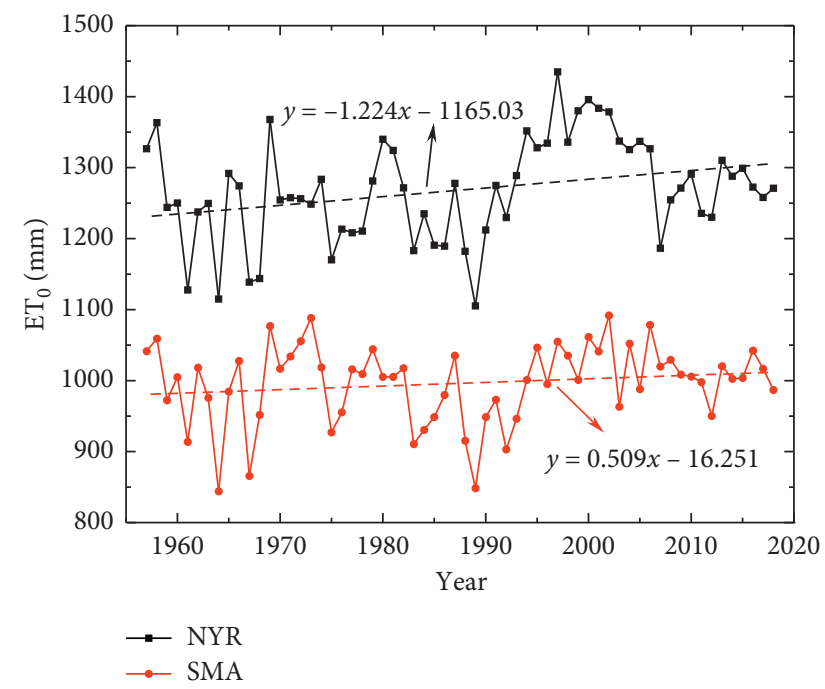

(b)

FIgUre 10: Temporal variations of annual $\mathrm{ET}_{0}$ from 1957 to 2018 over the NX, NYR, CAZ, and SMA. 
TABle 6: Multiyear average statistic value of $\mathrm{ET}_{0} / \mathrm{mm}$.

\begin{tabular}{lccc}
\hline Region & Minimum & Maximum & Average \\
\hline NYR & 1105.30 & 1434.91 & 1268.34 \\
CAZ & 1123.86 & 1434.19 & 1296.67 \\
SMA & 843.99 & 1091.92 & 996.19 \\
NX (whole) & 1063.42 & 1356.42 & 1222.41 \\
\hline
\end{tabular}

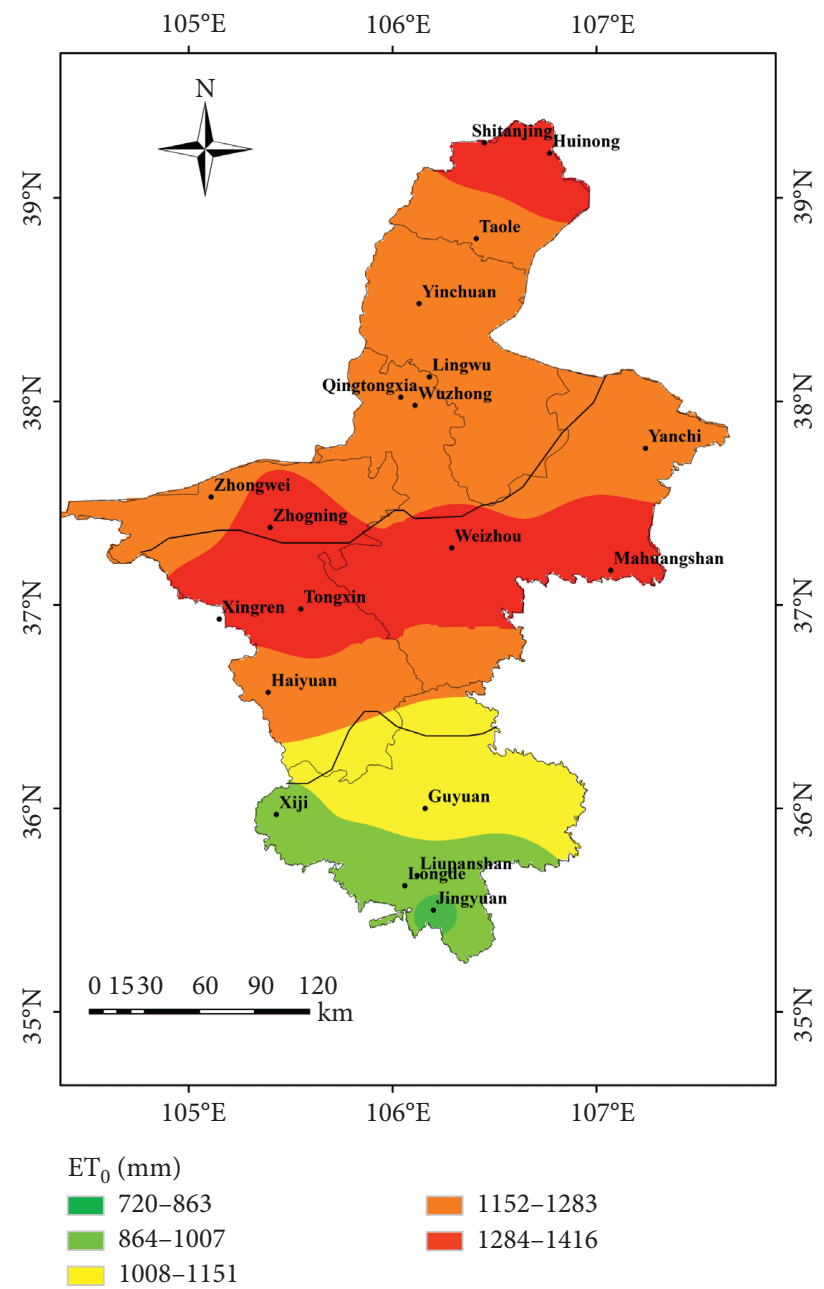

FIgURE 11: Spatial distribution of annual average $\mathrm{ET}_{0}$ in Ningxia.

As depicted in Figure 15, although the contribution rates of $T_{\max }, T_{\text {mean }}, T_{\min }$, and RH were all positive, the reason for the change in $\mathrm{ET}_{0}$ was exactly the opposite. Positive sensitive coefficient and positive climate trend rate of $T_{\max }, T_{\text {mean }}$, and $T_{\min }$ led to the positive contribution rate, while the sensitive coefficient and climate trend rate of RH both were negative. In particular, due to the positive sensitive coefficient and negative climate trend rate, the contribution rates of SD and $U_{2}$ were both negative, indicating that they led to the decline of $\mathrm{ET}_{0}$. In general, the most contribution rates in NX, NYR, CAZ, and SMA were $T_{\min }, T_{\min }, T_{\max }$, and $U_{2}$, respectively, while the SD was the smallest in all regions.

3.4.2. Analysis at Seasonal Scale. As for the seasonal scale, the sensitive coefficients of six climate factors were consistent with the annual scale. All showed that $T_{\text {mean }}, T_{\max }$, $T_{\min }, \mathrm{SD}, U_{2}$, and $\mathrm{RH}$ were positive values, while the $\mathrm{RH}$ was negative value (Table 8 ). In the spring and summer of NYR, CAZ, and NX, the most sensitive coefficient of main climate factors was $T_{\max }$, while the $\mathrm{RH}$ (absolute value) was the largest in autumn and winter. The SMA was different, and its most sensitive coefficient was always RH (absolute value) in four seasons. In addition, there were also two cases for the smallest sensitive coefficient of main climate factors, and it was $T_{\min }$ in four seasons of CAZ and NX. Moreover, the NYR and SMA were $T_{\min }$ in spring, summer, and autumn while SD in winter. Additionally, the sensitive coefficients of the main climate factors were also varying in the four seasons. The $T_{\text {mean }}, T_{\max }$, and SD showed an increase in trend first and then decrease, while the $U_{2}$ was the opposite. As for $T_{\min }$ and $\mathrm{RH}$, they were special, and $T_{\min }$ appeared as an alternating change in rise and decline, while $\mathrm{RH}$ was always showing an increase in trend.

As for the contribution rate depicted in Figure 16. In spring, SD and $U_{2}$ were negative values, whilst the $T_{\text {mean }}$, $T_{\max }, T_{\min }$, and $\mathrm{RH}$ were positive values. And the largest contribution rate in NYR and CAZ was RH, while the $U_{2}$ was largest in SMA and NX. Moreover, there was no regularity in summer and autumn. In summer, the largest contribution rates in NYR, CAZ, SMA, and NX were $U_{2}, T_{\max }, T_{\min }$, and $U_{2}$, respectively. And in autumn, the largest contribution rates were $T_{\max }, T_{\max }, T_{\text {mean }}$, and $U_{2}$, respectively. In winter, it was extremely consistent in different regions, in which the $T_{\max }$ was always the dominant factor. In addition, the climate factors varied from spring to winter, but it could be roughly divided into two situations. The $T_{\text {mean }}, T_{\max }$, and $T_{\min }$ were relatively regular, which showed a trend of decreasing first and then increasing. On the contrary, the SD, $U_{2}$, and RH did not show obvious regularity.

\section{Discussion}

4.1. Variation in Climate Factors. In the past thousand years, the temperature had showed an unprecedented upward trend, indicating the global warming as an indisputable fact. This study found that the Ningxia was suffering from climate warming (i.e., $0.34^{\circ} \mathrm{C} / 10 \mathrm{a}$ in $T_{\text {mean }}, 0.31^{\circ} \mathrm{C} / 10 \mathrm{a}$ in $T_{\max }$, and $0.51^{\circ} \mathrm{C} / 10 \mathrm{a}$ in $T_{\min }$ (Table 2)), which is consistent with most research in the past few decades [40] and almost triple the global temperature increasing rate shown in the IPCC Fifth Assessment Report $\left(0.12^{\circ} \mathrm{C} / 10 \mathrm{a}\right)$. The rise in temperature may be due to two reasons: one is the increase in solar radiation caused by the destruction of the ozone layer, and the other is the large amount of greenhouse gas emissions caused by economic development and population growth [41].

The $U_{2}$ showed a downward trend in Ningxia based on this study $(0.10 \mathrm{~m} / \mathrm{s} / 10 \mathrm{a}$, Table 2$)$, which was reported in some relevant studies [42]. The natural reason, internal role of the natural system, is the main reason for the decrease in wind speed, including the weakening of the East Asian winter monsoon and summer monsoon in recent decades [43]. Additionally, the SD also showed a decreasing trend in Ningxia $(0.03 \mathrm{~h} / 10 \mathrm{a}$, Table 2$)$, which is generally consistent 


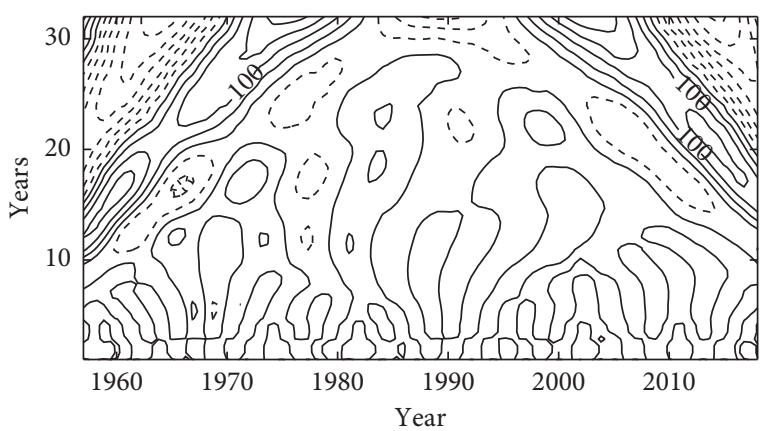

(a)

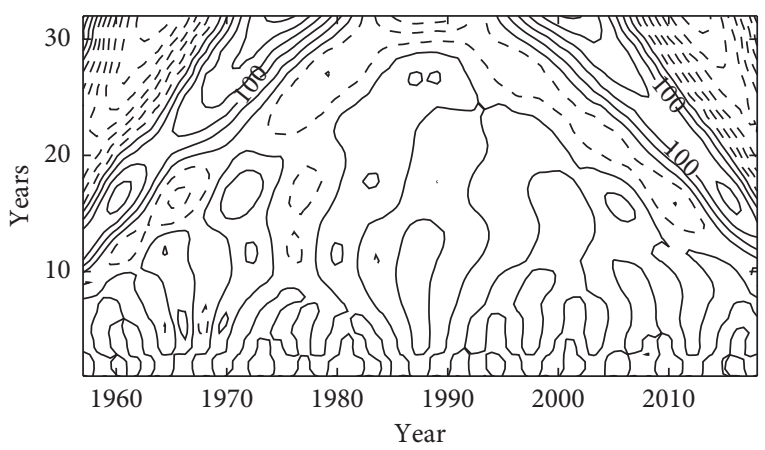

(c)

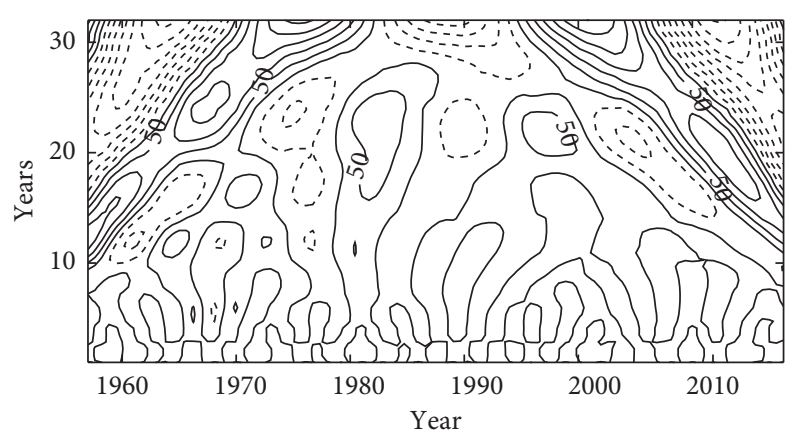

(b)

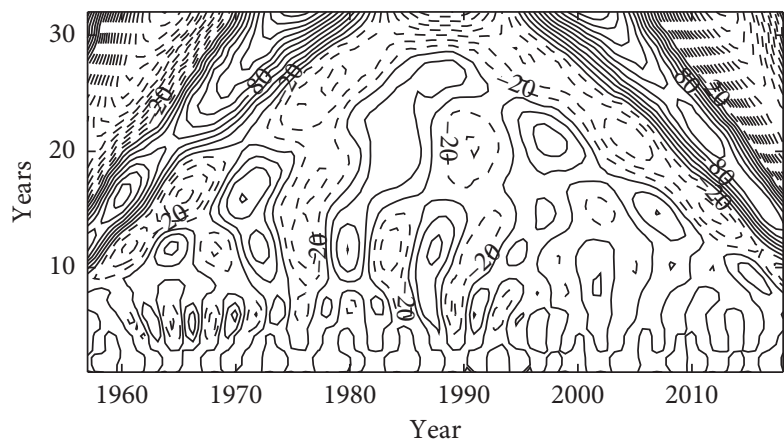

(d)

FIgURE 12: Wavelet analysis of each region at annual scale: (a) NX; (b) NYR; (c) CAZ; (d) SMA.
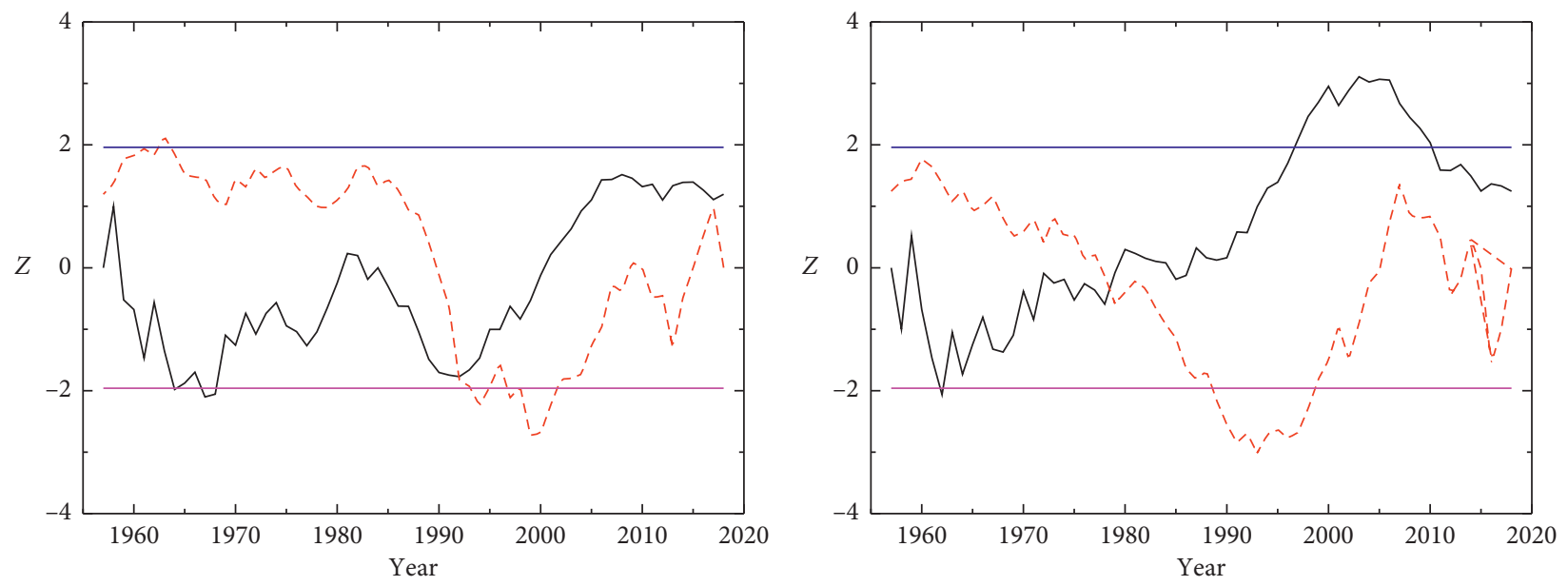

$$
- \text { UF }
$$$$
\begin{aligned}
& \text { U UF } \\
& -- \text { UB }
\end{aligned}
$$

(a)

FIGURE 13: Continued. 

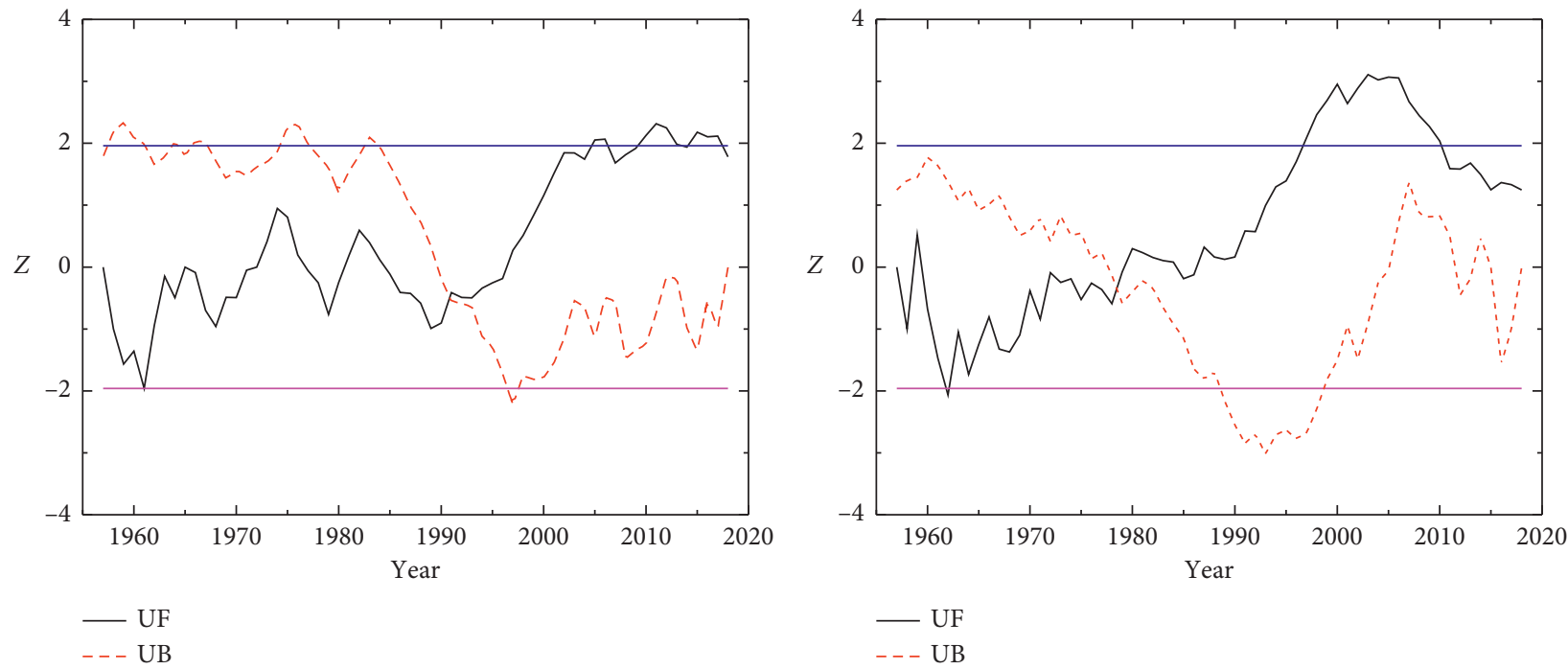

(c)

(d)

FIgURE 13: Mann-Kendall test of Ningxia at seasonal scale: (a) spring; (b) summer; (c) autumn; (d) winter.

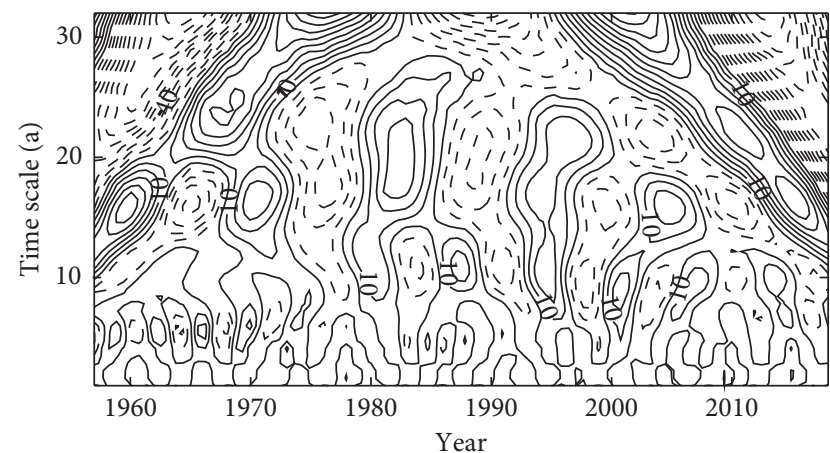

(a)

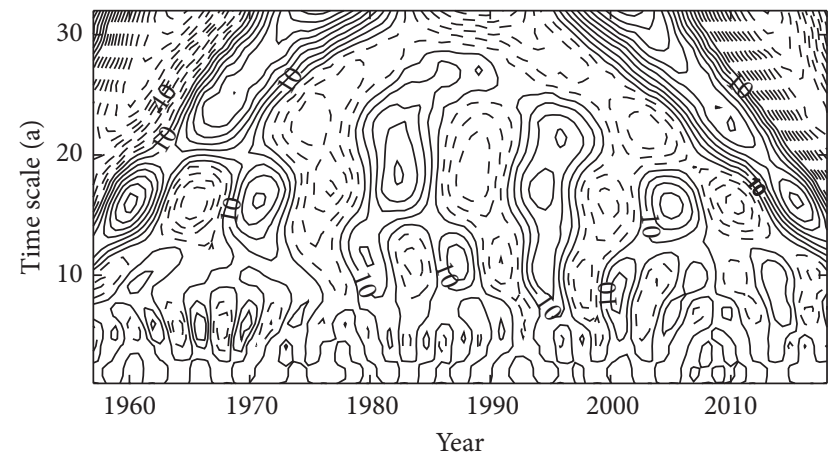

(c)

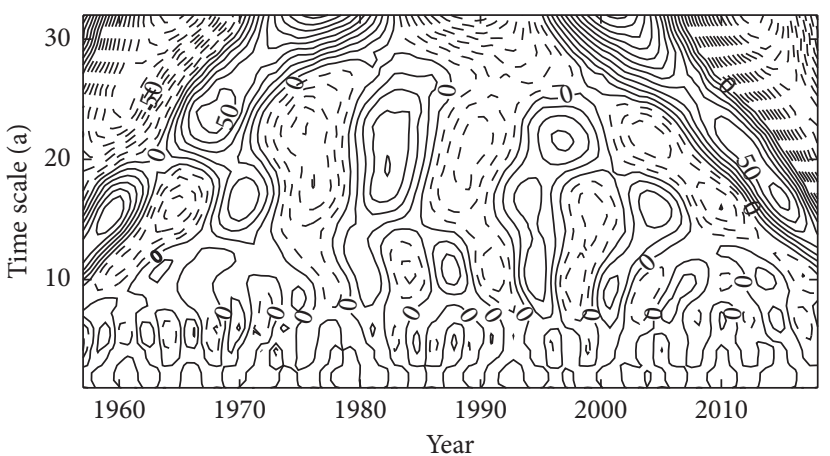

(b)

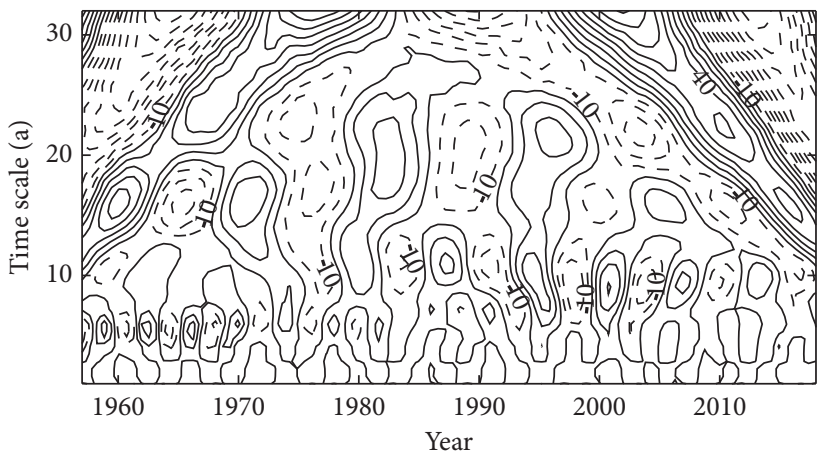

(d)

FIGURE 14: Wavelet analysis of each region at seasonal scale: (a) spring; (b) summer; (c) autumn; (d) winter.

Table 7: Sensitive coefficient of the main climate factors to $\mathrm{ET}_{0}$ from 1957 to 2018 in Ningxia at annual scale.

\begin{tabular}{lccccrr}
\hline Region & $T_{\text {mean }}$ & $T_{\max }$ & $T_{\min }$ & SD & $U_{2}$ & RH \\
\hline NYR & 0.25 & 0.37 & 0.09 & 0.15 & 0.29 & -0.45 \\
CAZ & 0.26 & 0.44 & 0.04 & 0.14 & 0.20 & -0.56 \\
SMA & 0.23 & 0.32 & 0.09 & 0.15 & 0.30 & -0.42 \\
NX & 0.24 & 0.35 & 0.08 & 0.15 & 0.28 & -0.46 \\
\hline
\end{tabular}




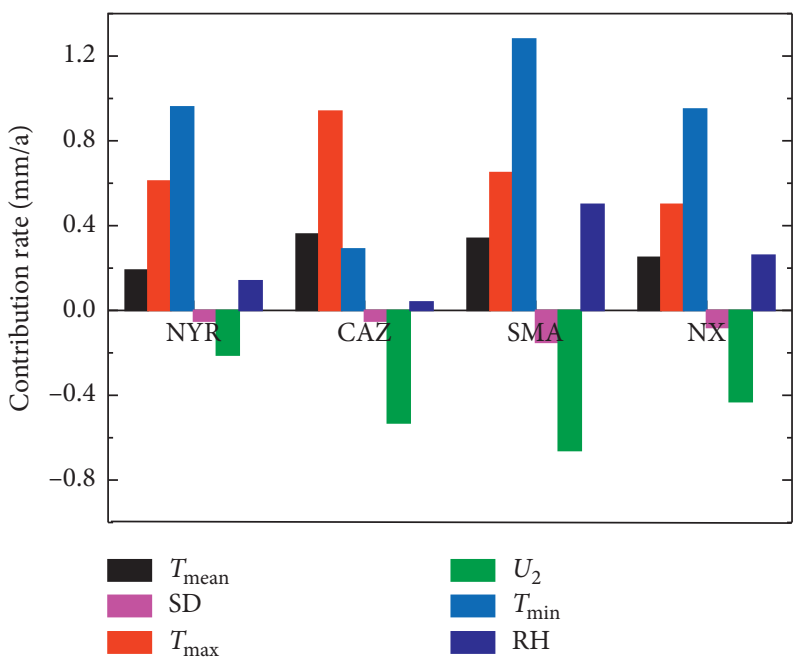

Figure 15: Contribution rate of the main climate factors in Ningxia at annual scale (mm/a).

TABle 8: Sensitive coefficient of the main climate factors to $\mathrm{ET}_{0}$ from 1957 to 2018 in Ningxia at seasonal scale.

\begin{tabular}{|c|c|c|c|c|c|c|c|}
\hline Region & Season & $T_{\text {mean }}$ & $T_{\max }$ & $T_{\min }$ & $\mathrm{SD}$ & $U_{2}$ & $\mathrm{RH}$ \\
\hline \multirow{4}{*}{ NYR } & Spring & 0.26 & 0.47 & 0.06 & 0.24 & 0.28 & -0.30 \\
\hline & Summer & 0.32 & 0.52 & 0.13 & 0.35 & 0.19 & -0.33 \\
\hline & Autumn & 0.24 & 0.42 & 0.06 & 0.20 & 0.30 & -0.54 \\
\hline & Winter & 0.11 & 0.10 & 0.12 & 0.04 & 0.42 & -0.59 \\
\hline \multirow{4}{*}{ CAZ } & Spring & 0.24 & 0.43 & 0.06 & 0.23 & 0.25 & -0.34 \\
\hline & Summer & 0.30 & 0.47 & 0.12 & 0.36 & 0.17 & -0.33 \\
\hline & Autumn & 0.21 & 0.37 & 0.06 & 0.22 & 0.26 & -0.48 \\
\hline & Winter & 0.28 & 0.43 & 0.12 & 0.42 & 0.41 & -0.48 \\
\hline \multirow{4}{*}{ SMA } & Spring & 0.16 & 0.29 & 0.03 & 0.25 & 0.23 & -0.36 \\
\hline & Summer & 0.19 & 0.31 & 0.08 & 0.39 & 0.13 & -0.35 \\
\hline & Autumn & 0.14 & 0.25 & 0.03 & 0.21 & 0.25 & -0.65 \\
\hline & Winter & 0.08 & 0.08 & 0.09 & 0.06 & 0.40 & -0.64 \\
\hline \multirow{4}{*}{ NX } & Spring & 0.23 & 0.42 & 0.04 & 0.24 & 0.25 & -0.33 \\
\hline & Summer & 0.29 & 0.46 & 0.11 & 0.36 & 0.18 & -0.34 \\
\hline & Autumn & 0.21 & 0.36 & 0.06 & 0.21 & 0.28 & -0.54 \\
\hline & Winter & 0.18 & 0.24 & 0.11 & 0.77 & 0.41 & -0.55 \\
\hline
\end{tabular}

with the existing finding [44]. There are different views on the reduction of sunshine hours, and decreased visibility due to rising aerosol content in the troposphere may be the main cause [45]. Similar to $U_{2}$ and SD, the RH showed a downward trend from 1957 to 2018 (0.42\%/10a, Table 2). And this result is coincident to the other studies [46]. The impact of climate change on $\mathrm{RH}$ is a complex issue, involving temperature, surface runoff, vegetation types, and even the underground water [47]. Therefore, it is difficult to determine the fundamental causes of RH change. Furthermore, this study found that the 1990s seemed to be a time code of abrupt change, in which the six climate factors were beginning to change before and after it. The temporal trend of the six climate factors in Ningxia is consistent with most of the findings, while there are minor differences in spatial distribution, which is mainly due to the form of climate data and the area size.

4.2. ET $T_{0}$ Trends and "Evaporation Paradox". As the rise in $T$ and the decrease in $U_{2}, \mathrm{RH}$, and $\mathrm{SD}$, the $\mathrm{ET}_{0}$ is generally considered to gradually increase. However, the performance of different regions in Ningxia is inconsistent. The annual and seasonal $\mathrm{ET}_{0}$ showed an increasing trend in $\mathrm{NX}$ (5.79 mm/10a), NYR (12.24 mm/10a), and SMA (5.09 mm/ 10a), while it was decreasing in CAZ $(4.52 \mathrm{~mm} / 10 \mathrm{a})$. This implied that there was "evaporation paradox" in the CAZ of Ningxia, and this estimate for $\mathrm{ET}_{0}$ was higher than the entire China (3.5 mm/10a) [34] and the Northern Loess Plateau of China (3.3 mm/10a) [9]. For decades, many scholars studied the causes of the "evaporation paradox" in different regions and have reached different conclusions [48, 49]. It is generally believed that there are three main reasons for the decline of $\mathrm{ET}_{0}$. The decrease in solar radiation was caused by the increase in atmospheric cloud amount (aerosol), and the decrease in water vapor pressure was caused by the increase in air humidity and the decrease in wind speed.

In order to obtain the cause of the evaporation paradox in the CAZ of Ningxia, the MODIS satellite data (MOD08) from 2000 to 2018 were selected to analyze the distribution and variation in cloud optical thickness and aerosol optical thickness. As depicted in Figure 17, the CAZ's annual 


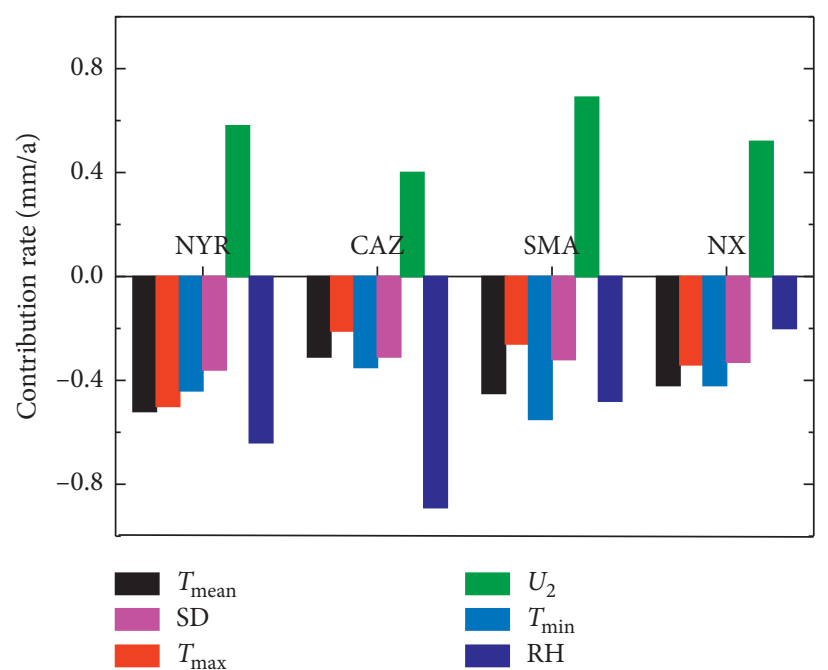

(a)

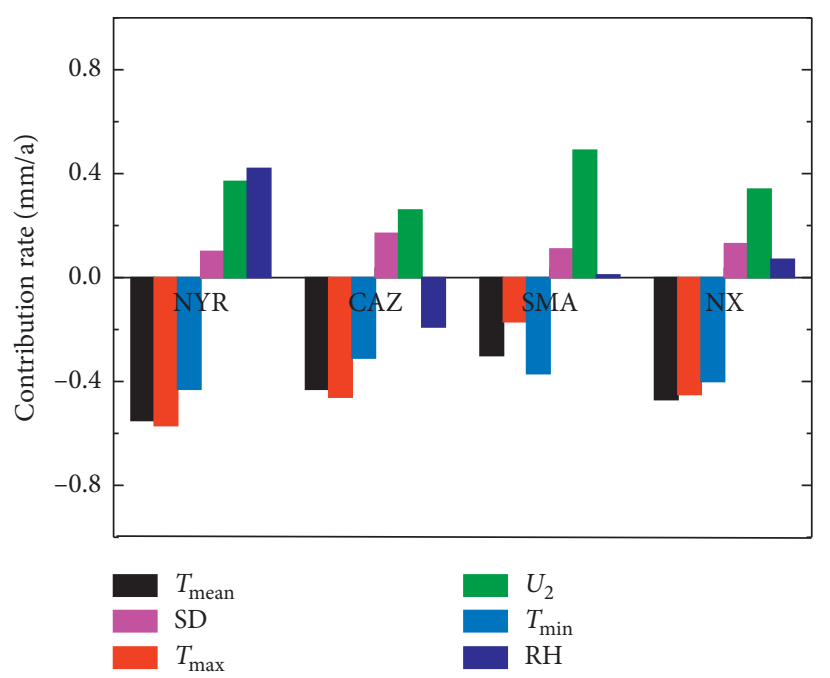

(c)

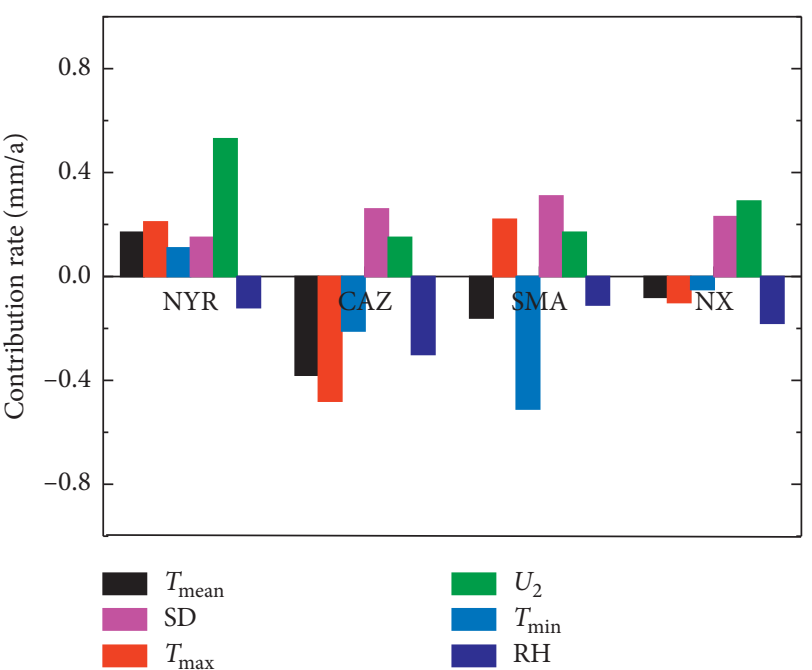

(b)

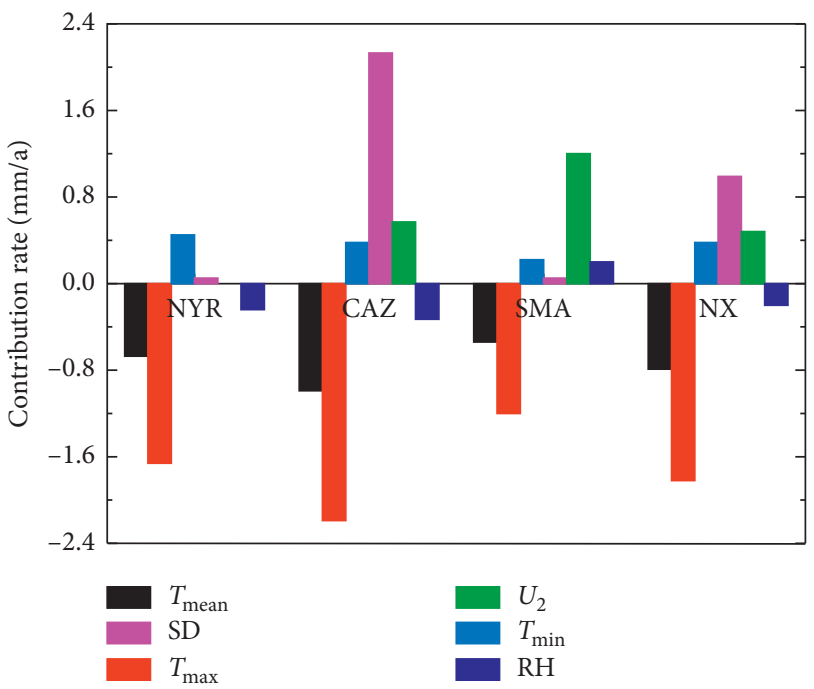

(d)

FIGURE 16: Contribution rate of the main climate factors in Ningxia at seasonal scale (mm/a): (a) spring; (b) summer; (c) autumn; (d) winter.

average cloud optical thickness is 24 in 2018, and the upward trend is very significant compared to 16 in 2000. Generally, the increase in the thickness of the cloud optics reduces the total amount of radiation reaching the ground. This study analyzed the total solar radiation variation in CAZ since 1957. The total radiation of CAZ had a significant downward trend from 1957 to $2018\left(-13.418 \mathrm{MJ} / \mathrm{m}^{2} / \mathrm{a}\right)$. In general, the increase in cloud optical thickness in CAZ led to a decrease in total solar radiation, which is the main reason for the decline in $\mathrm{ET}_{0}$.

4.3. The Impacts of Climate Change on the Variation in $E T_{0}$. The impact of climate factors on the contribution of $\mathrm{ET}_{0}$ changes is not only related to the sensitivity of $\mathrm{ET}_{0}$ but also to the changes in climate factors themselves. The sensitivity analysis at annual scale in this study showed that the $\mathrm{ET}_{0}$ in Ningxia was most sensitive to $\mathrm{RH}(-0.46)$, followed by $T_{\max }$ (0.35), $U_{2}(0.28), T_{\text {mean }}(0.24), \mathrm{SD}(0.15)$, and $T_{\min }(0.08)$,

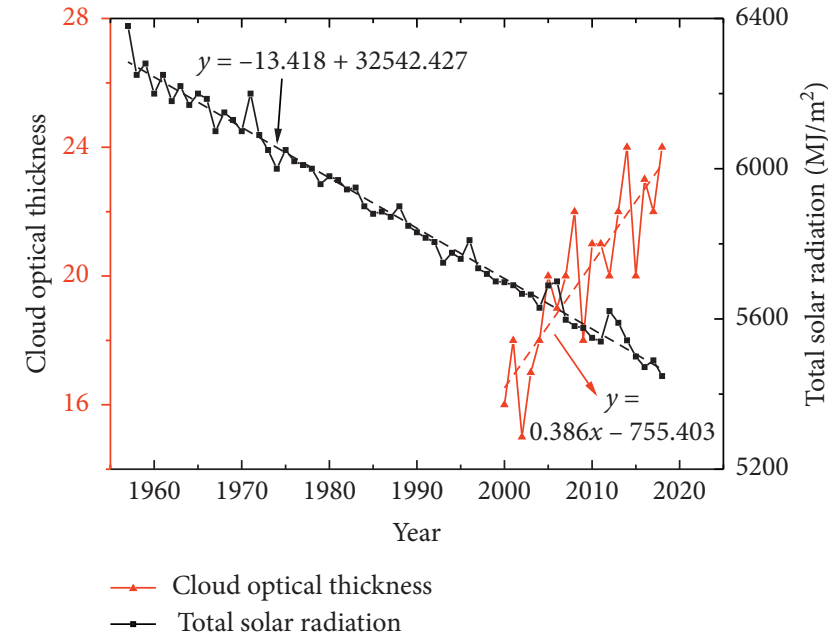

FIGURE 17: Annual variations in spatially averaged values of cloud optical thickness and total solar radiation. 
which is consistent with some relevant studies [41, 50]. Simultaneously, the positive changes in $\mathrm{ET}_{0}$ in Ningxia due to the relative increase in $T_{\max }$ was larger than other climate factors. And the relative contribution rate of $\mathrm{RH}$ was small although it was the most sensitive. Additionally, another explanation for what is known as "global dimming" in previous studies was the reduction in SD, which was the most important controlling factor leading to the reduction in $\mathrm{ET}_{0}$ [51]. Nevertheless, this study found that the $\mathrm{SD}$ had less contribution rate to $\mathrm{ET}_{0}$ in Ningxia compared to other climate factors. And this result is in accordance with Qi [30], who indicated that the SD had less influence on $\mathrm{ET}_{0}$ in Northeast China. Compared to the annual scale, the sensitivity analysis in this study illustrated that the $\mathrm{ET}_{0}$ in Ningxia at seasonal scale had no obvious regularity. The $T_{\max }$ was the most sensitive in spring (0.42) and summer (0.46), while the RH was the largest in autumn $(-0.54)$ and winter $(-0.55)$, and this is different from Wang [41], who found that $T_{\max }$ was the most sensitive to $\mathrm{ET}_{0}$ in four seasons. As for the contribution rate of Ningxia, it was similar to the sensitivity. And this is inconsistent with Thomas [52], who emphasized that the $U_{2}$ changes $\mathrm{ET}_{0}$ in water-limited areas of west China. The possible reason for this is that the climate difference among the three regions (NYR, CAZ, and SMA) of Ningxia was relatively large [53].

4.4. The Future Study of $E T_{0}$. $E T_{0}$ is significant for the water and energy balance of terrestrial ecosystems, and reasonable prediction of future $\mathrm{ET}_{0}$ is not only beneficial to water resources management but also important for guiding agricultural production [54]. Although Ningxia is deeply inland in the northwest of China, the $\mathrm{ET}_{0}$ is significant affected by the climate. Thus, we can study the $\mathrm{ET}_{0}$ from two perspectives in the future.

First, there are many atmospheric teleconnection patterns (i.e., Atlantic Oscillation (AO), the Indian Ocean Dipole (IOD), Pacific Decadal Oscillation (PDO), and El Niño-Southern Oscillation indices (ENSO)) in the global climate system and the effects of these atmospheric circulations have broken through time and space constraints. That is to say, the influence can occur simultaneously or sequentially in time, and the change can be far apart in space. Therefore, these atmospheric teleconnection models can change $\mathrm{ET}_{0}$ in annual and seasonal scales by affecting climatic factors. With a deep understanding of the atmospheric circulation system in the future, it is possible to take advantage of the atmospheric teleconnection models to predict future $\mathrm{ET}_{0}[23]$.

Second, the air temperature had increased over the past 50 years and is reported in Xinjiang [55], Gansu, [56] and Mongolia [57]. And McVicar observed a drying trend due to the reduced rainfall in northwest China [58]. The future study is necessarily motivated by the abovementioned considerations to assess sensitivity of the evapotranspiration due to $\pm 20 \%$ change in several climatic factors. Specially, the IPCC report for the $21^{\text {st }}$ century can be considered in the future study, which can describe and quantify the impacts of climatic factors on seasonal and annual $\mathrm{ET}_{0}$ based on the climate change [59].

\section{Conclusions}

The climate factors temporal trends, the spatiotemporal variation of $\mathrm{ET}_{0}$ at different time scales, and its climatic driving factors across different climatic zones of Ningxia were investigated with the climate tendency rate, Man$\mathrm{n}$-Kendall test, continuous wavelet analysis, sensitivity analysis, and contribution rate assessment based on daily data of 20 climatic stations from 1957 to 2018 . The main conclusions of this study are as follows:

(1) $T_{\text {mean }}, T_{\max }$, and $T_{\min }$ all have increased significantly over the past 62 years in Ningxia, whilst RH, $U_{2}$, and SD have significantly decreasing trends. And this trend has become more pronounced with 1990 as the abrupt change point.

(2) The $\mathrm{ET}_{0}$ is mainly concentrated from April to September in a year. In NX, NYR, and SMA, the $\mathrm{ET}_{0}$ series has a significant increase in both annual and seasonal scales, while CAZ is the opposite. In terms of spatial distribution at monthly, seasonal, and annual scales, there is a trend of increasing first and then decreasing from north to south.

(3) An abrupt change point in annual $\mathrm{ET}_{0}$ is detected around the year of 1990, and the annual $\mathrm{ET}_{0}$ decreased significantly from 1957 to 1990 , while it increased significantly from 1991 to 2018 . The $\mathrm{ET}_{0}$ has a long period of $25 \mathrm{a}$ and a short period of $10 \mathrm{a}$ at annual scale, while it is $15 \mathrm{a}$ and $5 \mathrm{a}$ at seasonal scale.

(4) At the annual and seasonal scales, the most sensitive climatic factors are $\mathrm{RH}$ and $T_{\max }$, while the largest contribution rates are $T_{\max }$ and SD.

The results of this study can not only help to guide the agricultural water management in Ningxia but also contribute to agricultural production and environmental protection. In the future work, the relationship between atmospheric circulation and $\mathrm{ET}_{0}$ can be analyzed for $\mathrm{ET}_{0}$ prediction, which is most significant for the researchers and decision makers.

\section{Data Availability}

The data used in this paper are provided by the National Meteorological Information Center (http://data.cma.cn).

\section{Conflicts of Interest}

The authors declare that they have no conflicts of interest.

\section{Authors' Contributions}

Ziyang Zhao contributed substantially to conceptualization, methodology, validation, data curation, data interpretation, and writing. All authors participated in drafting the article or revising it critically and gave final approval of the version to be submitted. 


\section{Acknowledgments}

This research was supported by the National Natural Science Foundation of China (Grant nos. 51879010 and 51479003), the National Key Research and Development Program of China (2018YFC0407900 and 2019YFC0408902), the Graduate Innovation Fund in Beijing Key Laboratory of Urban Hydrological Cycle and Sponge City Technology (HYD2020IFDC03), and the 111 Project (Grant no. B18006).

\section{References}

[1] S. Xu, Z. Yu, C. Yang, X. Ji, and K. Zhang, "Trends in evapotranspiration and their responses to climate change and vegetation greening over the upper reaches of the Yellow River basin," Agricultural and Forest Meteorology, vol. 263, pp. 118-129, 2018.

[2] D. Chen, G. Gao, C. Xu, J. Guo, and G. Ren, "Comparison of the Thornthwaite method and pan data with the standard Penman-Monteith estimates of reference evapotranspiration in China," Climate Research, vol. 28, no. 2, pp. 123-132, 2005.

[3] L. Gong, C.-y. Xu, D. Chen, S. Halldin, and Y. D. Chen, "Sensitivity of the Penman-Monteith reference evapotranspiration to key climatic variables in the Changjiang (Yangtze River) basin," Journal of Hydrology, vol. 329, no. 3-4, pp. 620-629, 2006.

[4] R. G. Allen, L. S. Pereira, M. Smith, D. Raes, and J. L. Wright, "FAO-56 dual crop coefficient method for estimating evaporation from soil and application extensions," Journal of Irrigation and Drainage Engineering, vol. 131, no. 1, pp. 2-13, 2005.

[5] L. S. Pereira, R. G. Allen, M. Smith, and D. Raes, "Crop evapotranspiration estimation with FAO56: past and future," Agricultural Water Management, vol. 147, pp. 4-20, 2015.

[6] N. S. Christensen, A. W. Wood, N. Voisin, D. P. Lettenmaier, and R. N. Palmer, "The effects of climate change on the hydrology and water resources of the Colorado River basin," Climatic Change, vol. 62, no. 1-3, pp. 337-363, 2004.

[7] G.-R. Walther, E. Post, P. Convey et al., "Ecological responses to recent climate change," Nature, vol. 416, no. 6879, pp. 389-395, 2002.

[8] X.-e. Tao, H. Chen, C.-y. Xu, Y.-k. Hou, and M.-x. Jie, "Analysis and prediction of reference evapotranspiration with climate change in Xiangiiang River basin, China," Water Science and Engineering, vol. 8, no. 4, pp. 273-281, 2015.

[9] T. Ning, Z. Li, W. Liu, and X. Han, "Evolution of potential evapotranspiration in the northern Loess Plateau of China: recent trends and climatic drivers," International Journal of Climatology, vol. 36, no. 12, pp. 4019-4028, 2016.

[10] C. Li, P. Wu, X. Li et al., "Spatial and temporal evolution of climatic factors and its impacts on potential evapotranspiration in Loess Plateau of Northern Shaanxi, China," Science of the Total Environment, vol. 589, pp. 165-172, 2017.

[11] M. Malte, M. Nicolai, H. William et al., "Greenhouse-gas emission targets for limiting global warming to $2^{\circ} \mathrm{C}$," Nature, vol. 458, no. 7242, pp. 1158-1162, 2009.

[12] R. K. Pachauri, M. R. Allen, V. R. Barros et al., Climate Change 2014: Synthesis Report. Contribution of Working Groups I, II, and III to the Fifth Assessment Report of the Intergovernmental Panel on Climate Change, IPCC, Geneva, Switzerland, 2014.

[13] A. Piticar, D. Mihăilă, L. G. Lazurca, P. I. Bistricean, A. Puţuntică, and A. E. Briciu, "Spatiotemporal distribution of reference evapotranspiration in the Republic of Moldova,"
Theoretical \& Applied Climatology, vol. 124, no. 3-4, pp. 1133-1144, 2016.

[14] G. Papaioannou, G. Kitsara, and S. Athanasatos, "Impact of global dimming and brightening on reference evapotranspiration in Greece," Journal of Geophysical Research, vol. 116, no. D9, 2011.

[15] A.-A. Sabziparvar, H. Tabari, A. Aeini, and M. Ghafouri, "Evaluation of class a pan coefficient models for estimation of reference crop evapotranspiration in cold semi-arid and warm arid climates," Water Resources Management, vol. 24, no. 5, pp. 909-920, 2010.

[16] K. Chaouche, L. Neppel, C. Dieulin et al., "Analyses of precipitation, temperature and evapotranspiration in a French Mediterranean region in the context of climate change," Comptes Rendus Geoscience, vol. 342, no. 3, pp. 234-243, 2010.

[17] L. Xu, Z. Shi, Y. Wang et al., "Spatiotemporal variation and driving forces of reference evapotranspiration in Jing River basin, northwest China," Hydrological Processes, vol. 29, no. 23, pp. 4846-4862, 2015.

[18] M. L. Roderick and G. D. Farquhar, "Changes in New Zealand pan evaporation since the 1970s," International Journal of Climatology, vol. 25, no. 15, pp. 2031-2039, 2005.

[19] M. T. Hobbins, J. A. Ramírez, and T. C. Brown, “Trends in pan evaporation and actual evapotranspiration across the conterminous U.S.: paradoxical or complementary?" Geophysical Research Letters, vol. 31, no. 13, pp. 405-407, 2004.

[20] Z. Li, F. Qi, L. Wei et al., "Spatial and temporal trend of potential evapotranspiration and related driving forces in Southwestern China, during 1961-2009," Quaternary International, vol. 336, no. 127-144, pp. 127-144, 2014.

[21] T. C. Peterson, V. S. Golubev, and P. Y. Groisman, "Evaporation losing its strength," Nature, vol. 377, no. 6551, pp. 687-688, 1995.

[22] D. Jhajharia, Y. Dinpashoh, E. Kahya, V. P. Singh, and A. Fakheri-Fard, "Trends in reference evapotranspiration in the humid region of Northeast India," Hydrological Processes, vol. 26, no. 3, pp. 421-435, 2012.

[23] R. Chai, S. Sun, H. Chen, and S. Zhou, "Changes in reference evapotranspiration over China during 1960-2012: attributions and relationships with atmospheric circulation," $\mathrm{Hy}$ drological Processes, vol. 32, no. 19, pp. 3032-3048, 2018.

[24] Z. Dan and X. Liu, "Assessing the effect of climate change on reference evapotranspiration in China," Stochastic Environmental Research \& Risk Assessment, vol. 27, no. 8, pp. 18711881, 2013.

[25] S. Xu, Y. Liu, X. Wang, and G. Zhang, "Scale effect on spatial patterns of ecosystem services and associations among them in semi-arid area: a case study in Ningxia Hui autonomous region, China," Science of The Total Environment, vol. 598, pp. 297-306, 2017.

[26] Y. L. Zhang, P. X. Liu, and Y. Wang, "Temporal and spatial variations of the drought in Ningxia based on aridity index and Morlet wavelet analysis," Chinese Journal of Ecology, vol. 34, no. 8, pp. 2373-2380, 2015.

[27] J. Liu, L. X. Wang, M. A. Li-Wen, W. U. Wan-Li, Y. L. Liu, and Y. C. Sun, "A loss estimation method of monitoring and estimating the yield loss of wheat by drought in dry farming areas in Northwest of China," Scientia Agricultura Sinica, vol. 37, no. 2, pp. 201-207, 2004.

[28] Y. Guan, L. Kang, C. Shao, P. Wang, and M. Ju, "Measuring county-level heterogeneity of $\mathrm{CO}_{2}$ emissions attributed to energy consumption: a case study in Ningxia Hui autonomous region, China," Journal of Cleaner Production, vol. 142, pp. 3471-3481, 2017. 
[29] R. Lyu, J. Zhang, M. Xu, and J. Li, "Impacts of urbanization on ecosystem services and their temporal relations: a case study in Northern Ningxia, China," Land Use Policy, vol. 77, pp. 163-173, 2018.

[30] H. Qi, F. Pan, X. Pan et al., "Dry-wet variations and cause analysis in Northeast China at multi-time scales," Theoretical \& Applied Climatology, vol. 133, no. 3-4, pp. 1-12, 2017.

[31] R. G. Allen, L. S. Pereira, D. Raes, and M. Smith, Crop Evapotranspiration-Guidelines for Computing Crop Water Requirements-FAO Irrigation and Drainage Paper 56, FAO, vol. 300, no. 9, Rome, Italy, 1998.

[32] Z. Liu, Y. Wang, M. Shao, X. Jia, and X. Li, "Spatiotemporal analysis of multiscalar drought characteristics across the Loess Plateau of China," Journal of Hydrology, vol. 534, pp. 281-299, 2016.

[33] L. Chen, Y. Wang, B. Touati et al., "Temporal characteristics detection and attribution analysis of hydrological time-series variation in the seagoing river of southern China under environmental change," Acta Geophysica, vol. 66, no. 5, pp. 1151-1170, 2018.

[34] J. Fan, L. Wu, F. Zhang, Y. Xiang, and J. Zheng, "Climate change effects on reference crop evapotranspiration across different climatic zones of China during 1956-2015," Journal of Hydrology, vol. 542, pp. 923-937, 2016.

[35] P. Lin, Z. He, J. Du, L. Chen, Z. Xi, and L. Jing, "Impacts of climate change on reference evapotranspiration in the Qilian Mountains of China: historical trends and projected changes," International Journal of Climatology, vol. 38, no. 7, pp. 2980-2993, 2018.

[36] Y. Ding, G. Ren, Z. Zhao et al., "Detection, causes and projection of climate change over China: an overview of recent progress," Advances in Atmospheric Sciences, vol. 24, no. 6, pp. 954-971, 2007.

[37] P. Shilong, C. Philippe, H. Yao et al., "The impacts of climate change on water resources and agriculture in China," Nature, vol. 467, no. 7311, pp. 43-51, 2010.

[38] B. Nijssen, G. M. O’Donnell, A. F. Hamlet, and D. P. Lettenmaier, "Hydrologic sensitivity of global rivers to climate change," Climatic Change, vol. 50, no. 1-2, pp. 143-175, 2001.

[39] J. Gao, "Some Views on Trend and Causes of Global Climate Change," Rural Eco-Environment, vol. 13, no. 4, pp. 43-47, 1997.

[40] L. Cui, L. Wang, Z. Lai, Q. Tian, W. Liu, and J. Li, "Innovative trend analysis of annual and seasonal air temperature and rainfall in the Yangtze River basin, China during 1960-2015," Journal of Atmospheric and Solar-Terrestrial Physics, vol. 164, pp. 48-59, 2017.

[41] Z. Wang, A. Ye, L. Wang, K. Liu, and L. Cheng, "Spatial and temporal characteristics of reference evapotranspiration and its climatic driving factors over China from 1979-2015," Agricultural Water Management, vol. 213, pp. 1096-1108, 2019.

[42] R. Yu, B. Wang, and T. Zhou, "Tropospheric cooling and summer monsoon weakening trend over East Asia," Geophysical Research Letters, vol. 31, no. 22, Article ID L22212, 2004.

[43] Y. JIANG, Y. Luo, Z. Zhao et al., "Projections of wind changes for 21 st century in China by three regional climate models," Chinese Geographical Science, vol. 20, no. 3, pp. 226-235, 2010.

[44] H. C. Power, "Trends in solar radiation over Germany and an assessment of the role of aerosols and sunshine duration," Theoretical \& Applied Climatology, vol. 76, no. 1-2, pp. 47-63, 2003.
[45] Z. Li, W. Zhang, Y. He et al., "Decreasing trend of sunshine hours and related driving forces in Southwestern China," Theoretical and Applied Climatology, vol. 109, no. 1-2, pp. 305-321, 2012.

[46] B. Xie, Q. Zhang, and Y. Ying, "Trends in precipitable water and relative humidity in China: 1979-2005," Journal of Applied Meteorology and Climatology, vol. 50, no. 10, pp. 1985-1994, 2011.

[47] A. J. Simmons, K. M. Willett, P. D. Jones, P. W. Thorne, and D. P. Dee, "Low-frequency variations in surface atmospheric humidity, temperature, and precipitation: inferences from reanalyses and monthly gridded observational data sets," Journal of Geophysical Research, vol. 115, no. D1, 2010.

[48] Y. Zhang, C. Liu, Y. Tang, and Y. Yang, "Trends in pan evaporation and reference and actual evapotranspiration across the Tibetan Plateau," Journal of Geophysical Research, vol. 112, no. D12, 2007.

[49] Z. Zhu, S. Piao, Y. Xu, A. Bastos, P. Ciais, and S. Peng, "The effects of teleconnections on carbon fluxes of global terrestrial ecosystems," Geophysical Research Letters, vol. 44, no. 7, pp. 3209-3218, 2017.

[50] C. Liu, D. Zhang, X. Liu, and C. Zhao, "Spatial and temporal change in the potential evapotranspiration sensitivity to meteorological factors in China (1960-2007)," Journal of Geographical Sciences, vol. 22, no. 1, pp. 3-14, 2012.

[51] G. Kitsara, G. Papaioannou, A. Papathanasiou, and A. Retalis, "Dimming/brightening in athens: trends in sunshine duration, cloud cover and reference evapotranspiration," Water Resources Management, vol. 27, no. 6, pp. 1623-1633, 2013.

[52] A. Thomas, "Spatial and temporal characteristics of potential evapotranspiration trends over China," International Journal of Climatology, vol. 20, no. 4, pp. 381-396, 2015.

[53] Y. H. Ding, W. Wang, X. G. Chen, G. F. Zheng, J. Shao, and J. I. Xiao-Ling, "Analyses on climate characteristic and variation rule of rainstorm in Ningxia in recent 44 years," Plateau Meteorology, vol. 26, no. 3, pp. 630-636, 2007.

[54] Z. Zhao, H. Wang, C. Wang, W. Li, H. Chen, and C. Deng, "Changes in reference evapotranspiration over Northwest China from 1957 to 2018: variation characteristics, cause analysis and relationships with atmospheric circulation," Agricultural Water Management, vol. 231, Article ID 105958, 2020.

[55] Y. Xue, P. Han, and G. Feng, "Change trend of the precipitation and air temperature in Xinjiang since recent 50 years," Arid Zone Research, vol. 20, no. 2, pp. 127-130, 2003.

[56] R. Dou, J. Yan, and P. Wang, "Spatiotemporal distribution of temperature in Gansu province under global climate change during the period from 1956 to 2012," Arid Zone Research, vol. 32, no. 1, pp. 73-79, 2015.

[57] Z. Ma, H. Yu, Q. Zhang, and C. Cao, "Characteristics and abrupt change of temperature and precipitation in inner Mongolia area over the period 1960-2016," Research of Soil and Water Conservation, vol. 26, no. 3, pp. 114-121, 2019.

[58] T. R. McVicar, M. L. Roderick, R. J. Donohue et al., "Global review and synthesis of trends in observed terrestrial nearsurface wind speeds: implications for evaporation," Journal of Hydrology, vol. 416-417, pp. 182-205, 2012.

[59] S. Adnan, K. Ullah, A. H. Khan, and S. Gao, "Meteorological impacts on evapotranspiration in different climatic zones of Pakistan," Journal of Arid Land, vol. 9, no. 6, pp. 938-952, 2017. 